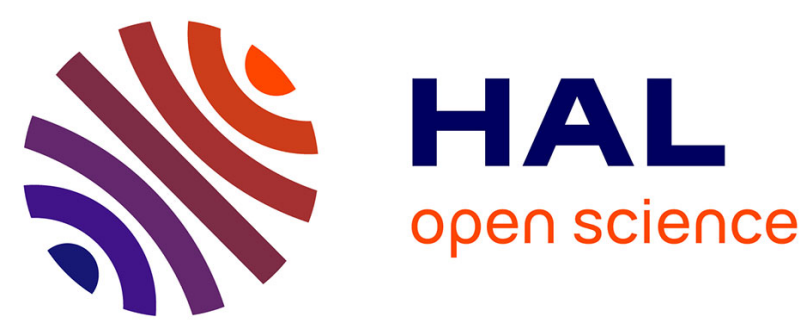

\title{
Is Dedekind a Logicist? Why does such a question arise?
}

\author{
Hourya Benis Sinaceur, Marco Panza, Gabriel Sandu
}

\section{To cite this version:}

Hourya Benis Sinaceur, Marco Panza, Gabriel Sandu. Is Dedekind a Logicist? Why does such a question arise?. Shahid Rahman, John Symons. Functions and Generality of Logic. Reflexions on Dedekind's and Frege's Logicisms, 37, Springer, 2015, Logic, Epistemology, and the Unity of Science, 978-3-319-17108-1. 10.1007/978-3-319-17109-8_1 . hal-01263755

\section{HAL Id: hal-01263755 \\ https://hal.science/hal-01263755}

Submitted on 29 Nov 2018

HAL is a multi-disciplinary open access archive for the deposit and dissemination of scientific research documents, whether they are published or not. The documents may come from teaching and research institutions in France or abroad, or from public or private research centers.
L'archive ouverte pluridisciplinaire HAL, est destinée au dépôt et à la diffusion de documents scientifiques de niveau recherche, publiés ou non, émanant des établissements d'enseignement et de recherche français ou étrangers, des laboratoires publics ou privés. 
Hourya Benis Sinaceur

Université Paris 1 Panthéon-Sorbonne, CNRS, ENS

UMR 8590 IHPST - Institut d'Histoire et de Philosophie des Sciences et des Techniques

Hourya.Sinaceur@ens.fr

houryabenis@yahoo.fr

\title{
Is Dedekind a logicist? Why does such a question arise?
}

\author{
Hourya Benis-Sinaceur, Marco Panza, Gabriel Sandu
}

\begin{abstract}
Dedekind shares Frege's aim of substituting logical standards of rigour for intuitive imports from spatio-temporal experience into the deductive presentation of arithmetic. But sharing this aim does not mean having the same fundamental goal nor using or inventing the same tools. I will highlight the basic dissimilarities between Dedekind's and Frege's actual ways of doing and thinking. Let us not be misguided by words: a contextual and comparative analysis shows indeed that Dedekind gives to the terms 'logic', 'number', 'thought', 'pure thought', 'laws of thought, 'concept', 'object', 'function' a radically different meaning from that which Frege's work made familiar to most of us. In the light of his semantic and practical background, Dedekind's famous assertion that arithmetic is "a part of logic", which has been taken as an expression of something close to Frege's logicism, does not mean, in my reading, that arithmetic is reducible to logic, but on the contrary, that arithmetic, intrinsically, constitutes a purely rational (logical in a pre-Fregean sense) norm of thinking. The Dedekidian "logic of the mind" is arithmetic generalized to undetermined elements.
\end{abstract}

Keywords

Abstraction, arithmetic, axiomatic, concept, definition, foundation, identity, law of thought, logicism, number, structuralism.

2014-03-10. Revised 2014-09-13 


\section{Introduction}

Logicism is the philosophical theory that arithmetic, and therefore all of mathematics, can be deduced from logic alone or can be reduced to logic. Logicism is prominently associated with Frege's and Russell's achievements, which are taken as paradigmatic realizations of the logicist aims. In Carnap's terms:

Logicism is the thesis that mathematics is reducible to logic, hence nothing but a part of logic. Frege was the first to espouse this view (1884). In their great work, Principia Mathematica, the English mathematicians A. N. Whitehead and B. Russell produced a systematization of logic from which they constructed mathematics ${ }^{1}$.

On the one hand, even though Dedekind writes, in the first preface to Was sind und was sollen die Zahlen ${ }^{2}$ (1888), that arithmetic is a part of logic, Carnap does not mention him. On the other hand, some recent investigations, especially the studies by Boolos, have shown that if one wants to take the logicism credo à la lettre, neither Frege's foundation of arithmetic nor Whitehead and Russell's presentation of arithmetic in Principia Mathematica can be really called logicist ${ }^{3}$. Boolos' main argument is the fact that the fundament of Frege's reduction, i.e. the definition of numerical equality in terms of the one-to-one correspondence, named Hume's principle (HP) ${ }^{4}$, is demonstrably consistent ${ }^{5}$ but not purely logical ${ }^{6}$.

Thus the state of affairs with logicism is not straightforward, even if one only considers the great father of logicism, Frege. Frege's great inventions (the function-argument analysis, the distinction between Sinn and Bedeutung, between concept and object, etc.) have given birth to

\footnotetext{
${ }^{1}$ Carnap 1931, my italics.
}

${ }^{2}$ Hereafter $Z$.

${ }^{3}$ Boolos' statement is more general: "Neither Frege nor Dedekind showed arithmetic to be part of logic. Nor did Russell. Nor did Zermelo or von Neumann. Nor did the author of Tractatus 6.02 or his follower Church. They merely shed light on it" (Boolos 1998, 216-217).

${ }^{4}$ Die Grundlagen der Arithmetik (hereafter $G l$ ), §63. Frege states (§69): "the extension of the concept 'equinumerous to the concept $F$ ' is equal to the extension of the concept 'equinumerous to the concept $G$ ' iff the same number belongs to the concept $F$ as to the concept $G$ ", i.e. HP is: $\forall F \forall G(\# F=\# G \leftrightarrow F \approx G), F \approx G$ being a second-order formula expressing the existence of a one-one correspondence between the objects falling under $F$ and those falling under $G$. Second-order logic +HP is called Frege's arithmetic (FA). On the differences between Hume's statement about numbers and Frege's application to concepts see Tait (1997) who rightly points out that the very definition of equinumerosity in terms of oneone correspondence is due to Cantor.

${ }^{5}$ Wright 1983; Hodes 1984, 138; Burgess 1984; Boolos 1998, 174, 183ff. HP has models with countable infinite domains.

${ }^{6}$ Boolos 1998, chap.19. Frege claims ( $\left.G l \S 72\right)$ that he has reduced one-to-one correspondence to purely logical relationships. Frege's attempt to derive HP from his definition of numbers (§73) appeals to his theory of concepts and objects, whose inconsistency Russell pointed out in his first letter to Frege (June 10, 1902). 
a huge amount of comments, interpretations, and debates in logic and the philosophy of mathematics. To deal with Frege's heritage is far beyond the scope of this paper. I shall rather focus on Frege's logicist project, not on its failure and its modern amendments.

Dedekind's construction of the natural numbers in $Z$ and, secondarily, of the real numbers in Stetigkeit und irrationale Zahlen ${ }^{7}$ (1872) are also often viewed as a "logicist foundation" of arithmetic. This view is based on some assertions in $Z$, mainly in the first preface. Actually, Dedekind shares Frege's aim of substituting logical standards of rigour for intuitive imports from spatio-temporal experience into the deductive presentation of arithmetic ${ }^{8}$. But sharing this aim does not mean having the same fundamental goal, nor following the same path to reach it. I will highlight the dissimilarities between Dedekind's and Frege's actual ways of doing and thinking and I will bring out the fact that "there are considerable differences in their accounts of our knowledge of the existence and infinity of natural numbers"9.

Moreover, pairing Dedekind with Frege often implies a distorted assessment of Dedekind's own achievements in $Z$ or in $S$ : by the yardstick of logic and logicism proper, $Z$ seems less "deep" and less thorough than Frege's Gl, without speaking of Grundgesetze der Arithmetik ${ }^{10}$, which set out the content of $G l$ in the frame of the formal language introduced in the Begriffsschrift ${ }^{11}$. For instance, Boolos thinks that what is missing in Dedekind's foundation of arithmetic is "any rigorous or even plausible derivation" of his axioms from something like $\mathrm{HP}^{12}$. Such a derivation of arithmetic in second-order logic, which is outlined in $G l$ and worked out by Wright, is called "Frege's theorem"13. Thus, Boolos' criticism comes down to saying that Dedekind did not prove "Frege's theorem"14, which is hardly surprising, since

\footnotetext{
${ }^{7}$ Hereafter $S$.

${ }^{8}$ E.g. Gödel $(1944,127)$ writes that the vicious circle principle "makes impredicative definitions impossible and thereby destroys the derivation of mathematics from logic, effected by Dedekind and Frege, and a good deal of modern mathematics itself." (my italics).

9 Demopoulos \& Clark 2005, 152 (my italics). I don't agree that Dedekind's 'thoughts' in Z 66 are thoughts in Frege's sense: they are not self-subsistent objects.

${ }^{10}$ Hereafter $G g$.

${ }^{11}$ Hereafter $B g$.

12 Boolos 1998, 140-141, and before: Parsons 1965, Heck 1993. More exactly Boolos means that PA, i.e. second-order logic together with the Dedekind-Peano axioms, can be derived from $\mathrm{FA}=$ an equivalent of HP within pure second-order logic, (details in chap.12, 183ff; again chap.17, 277ff.; chap.19). FA is equi-consistent with second-order arithmetic (Boolos 1998, 210, chap.18, 19).

${ }_{14}^{13}$ Boolos 1998, 209, and before Parsons 1965, 180-203; Wright 1983, chap.4.

${ }^{14}$ Boolos relies on the fact that from HP one can prove the existence of Dedekind infinite sets ( $A$ is Dedekind infinite when there is a bijection $\varphi$ from $A$ onto a proper subset of $A$. For getting Dedekind infinite sets we need the infinity axiom + an equivalent of the axiom of choice).
} 
Dedekind's aim was not to derive his axioms from something else but to lay them down as primitive and to derive from them the definition of natural numbers and arithmetical operations. Boolos considers that deriving mathematical induction was central in Frege's and Russell's attempts to provide a logical foundation for mathematics, as it also is a central goal when, following Zermelo, mathematics is developed in a set-theoretic framework ${ }^{15}$. But, Dedekind's interest was not to derive mathematical induction from a demonstrably purely logical principle. Dedekind derives mathematical induction from his concept of chain ${ }^{16}$, which is construed out of a System $S$ and an Abbildung $\varphi$ with domain and codomain $S^{17}$. Dedekind takes those concepts as resulting from two grounding operations: making a System from a multiplicity, representing a thing by a thing ${ }^{18}$, which are taken to be "logical" in the sense that 1) they are more general than the usual arithmetic operations and 2) they constitute the creative power of the mind. Besides that and above all else, Dedekind's first concern is not the question "How many?", therefore not the definition of cardinal numbers and not the numerical identity (equinumerosity). Dedekind assumes Leibniz's indiscernible principle ${ }^{19}$, making the most of the idea of substitutability rather than of the narrower idea of equational identity.

Dedekind's philosophical assumptions are less explicit and much less systematic than those of Frege; one might then be tempted to interpret them as germs of Frege's definite standpoint. Such a view can even be supported by the fact that Frege, at the time of $G g$, knew Dedekind's essays on numbers: from $Z$ he took, e.g., the term 'Abbildung, ${ }^{20}$, which did not appear in $B g^{21}$

\footnotetext{
${ }^{15}$ Boolos 1998, 345.
}

${ }^{16} Z 59$.

${ }^{17}$ Russell writes: "It is a most remarkable fact that Dedekind's previous assumptions suffice to demonstrate this theorem" (1903, 247).

${ }^{18}$ I keep untranslated Dedekind's term 'System' which corresponds to our 'set', and the terms 'Abbilden' and 'Abbildung' which do not correspond to our mapping and map. Dedekind does not define an Abbildung by its graph as is defined a map in current set theory. The first translation: 'representation', made by Russell 1903 and Zermelo 1909, seems much better to me. In the light of Emmy Nother's developments and of Category theory the operation of representing a thing by a thing is a morphism.

${ }^{19} Z 1$ : " A thing is completely determined by all that can be affirmed or thought concerning it. A thing $a$ is the same as $b$ (identical with $b$ ), and $b$ the same as $a$, when all that can be thought concerning $a$ can also be thought concerning $b$, and when all that is true of $b$ can also be thought of $a$ ".

${ }^{20} \mathrm{Gg} \S 53$.

${ }^{21}$ In Bg, Frege uses the terms 'Function' and 'Verfahren' (continually in $\left.§ \S 24-31\right)$. 'Abbilder' appears once, in $\S 13:$ "Diese Regeln und die Gesetze deren Abbilder sie sind, können in der Begriffsschrift deshalb nicht ausgedrückt werden, weil sie ihr zu Grunde liegen”. In $G l$, 'Verfahren' is replaced by 'Beziehung' (§§76ff.). Frege also uses 'eindeutige Zuordnung' 
nor in $G l$; in $\S \S 138-140,145-147$, he examines thoroughly $S$. One might also mention in passing that Frege quotes many times in $G l(\S \S 12,26,34$, etc.) Lipschitz's Lehrbuch der Analysis $^{22}$, which was written down after harsh discussions with Dedekind on the definition of the "continuity" of the domain of the real numbers: the operations on limits are introduced following $S \S 7$. Moreover, as Heck shows $(1993,598)$ on the basis of Parson’s insights, Frege states in $G g$ II four axioms closely related to, though different from, Dedekind's conditions $\alpha$, $\beta, \gamma, \delta$ of $Z 71$. More exactly, Frege proves the validity of definition by recursion over the natural numbers (theorem 263) and the isomorphism between relations together with fields that satisfy his own four axioms, both theorems already established in $Z, 126,132$. It is difficult to say how much Frege was inspired by his reading of $Z$, but one thing is clear: Frege does not isolate there the basic general logical laws, but the basic especial laws for arithmetic; thus, he strays far from $G l$ and comes close to an axiomatic conception of arithmetic. All these facts hint that, from 1879 onwards, Frege is familiar with Dedekind's works. By contrast, Dedekind comments very briefly on $G l$ in the second preface of $Z$ (1893) and focuses on mathematical induction, the very arithmetical method. It is also striking that after he became aware of the logical paradox involved in his construction and having had it pointed out several times to him by Cantor, he did not even try to amend anything. No attempt like that of the Appendix to $G g$ II after the discovery of "Russell's paradox" can be found in Dedekind's work. In the Preface to the third edition of $Z$ (1911), Dedekind affirms that "his trust in the internal harmony of our logic is not shaken" and he expressed his conviction that some means will certainly be found out in order to ground rigorously "the creative force thanks to which our mind creates out of some determinate elements a new element which is the System of them". "Our logic" is obviously not "logic" simpliciter. So, to say that Dedekind's logical achievements are less thorough than those of Frege is commonplace. But are logical investigations as such Dedekind's concern? One may have one's doubts.

While a comparison between Dedekind and Frege is very instructive ${ }^{23}$, it seems to me inadequate to assess the contribution of the first by standards provided by the second (nor the reverse, but that is rarely the case). Even if their works are classified together "for good

(§62), 'beiderseits eindeutige Zuordnung' (§72) and 'beiderseits eindeutige Beziehung' $(\S \S 78.5,84)$ for expressing one-to-one relation, which is, in Dedekind's terms, 'ähnliche Abbildung'. For Frege "der Beziehungsbegriff gehört also wie der einfache der reinen Logik an. Es kommt hier nicht der besondere Inhalt der Beziehung in Betracht, sondern allein die logische Form" (§70).

${ }^{22}$ Lipschitz 1877.

${ }^{23}$ See Belna 1996, Tait 1997. 
reasons" 24 , we have to consider Dedekind's own way of viewing "logic" as a ground for arithmetic. Isn't it strange to value this way through questions that it was not designed to take on? If one keeps uniquely to Frege's conception, one cannot understand why Peano built on Dedekind's rather than on Frege's axioms; and one comes to misjudge Dedekind's main contribution, which was mathematical and quickly played a leading part in mathematical $\operatorname{advances}^{25}$. For instance, some outstanding interpreters of Frege's work disregard the fundamental difference between Dedekind's foundation of real numbers and that of Cantor or Weierstraß. However, the former is not based on the concepts of limit and convergence, just inversely Dedekind shows how to derive the concept of limit, and thus the usual theorems of Real Analysis, from the purely arithmetical definition of the concept of real number ${ }^{26}$. This beautiful result and the underlying account of number exemplify how much Dedekind's view of arithmetic within the mathematical body and in respect of human understanding differs from Frege's one.

Having said enough for justifying a thorough re-assessment of Dedekind's own contributions to the foundations of arithmetic, I will begin by a quick survey of the literature making a comparison between Dedekind and Frege.

\section{Preliminary remarks: some excerpts from the literature}

There are many discussions on whether one could or could not assimilate Dedekind's foundational views with Frege's central thesis about the derivation of mathematics from pure logic. I will quote here only some of them. Philip Kitcher begins his 1986 paper with the remark that, since "our current understanding of what philosophy of mathematics might to be is so dominated by Frege's view of the field... Dedekind appears to us a lesser Frege, a man who groped toward some Fregean insights but who only saw dimly what Frege saw clearly". Kitcher is describing here the general opinion of philosophers who know better Frege's work; Kitcher himself he is at pains to rightly distinguish Dedekind's from Frege's philosophy. However, he finally argues that Dedekind developed "a version of the logicist thesis" "27 . A version", that already hints to sizeable differences between Frege and Dedekind. For Howard

\footnotetext{
${ }^{24}$ Parsons 1990, 339, footnote 6.

${ }^{25}$ In 1877 Felix Klein writes to Dedekind: "Nothing that you have created in your solitary reflection went unheeded in the long term, everything decisive at its time has intervened in the development of mathematics, where it fructifies in a hundredfold way." (Dugac 1976, 221).

${ }^{26}$ See my presentation of $S$ in Dedekind 2008.

${ }^{27}$ Kitcher 1986, 312.
} 
Stein, whose appraisal of Dedekind's work is illuminating, "Dedekind is a very important precursor of Hilbert as well as of logicism" 28 . While Dedekind is certainly a precursor of Hilbert, he is not, in my opinion, a precursor of Frege, whereas Hilbert has certainly inherited from Dedekind as well as from Frege and Russell-Whitehead for conceiving of the foundations of arithmetic and logic simultaneously ${ }^{29}$, since it became obvious that no logic can be built up without presupposing arithmetic in some form or other. Tait, who is annoyed by the tendency to enhance Frege's "superior clarity of thought and powers of conceptual analysis", supports the view of the logicism of Dedekind in the sense that "Dedekind and Frege seem to agree on a conception of logic as comprising the most general truths, which do not concern any special subject matter" ${ }^{\prime 30}$. He takes at face value Dedekind's assertion that arithmetic is a part of logic and attributes unquestionably Dedekind's Abbilden-ability to $\operatorname{logic}^{31}$. Ferreirós (1999) also describes Dedekind's position as amounting to a logicist foundation $^{32}$. More recently, William Demopoulos and Peter Clark have written the chapter 5 of Shapiro (2005) with the title: "The logicism of Frege, Dedekind, and Russell". For his part, Shapiro (2000) develops as a neo-Fregean programme a technical treatment of real analysis using Dedekind's cuts instead of Frege's HP. Shapiro's treatment shows the possibility of developing a "Dedekindian logicism", which is naturally not to be found in Dedekind's works. In a different direction, E. Reck (2003) considers different plausible interpretations of Dedekind's assertions, and calls Dedekind's specific position "logical structuralism". Ferreirós modified position is in favour of a "structural logicism" "33. Thus the question 'Is Dedekind a logicist?' is justified because a clear-cut answer is not obvious. Speaking of "Dedekind's logicism" everybody feels it necessary to qualify the term 'logicism' instead of using it purely and simply. And as one might expect, Kitcher, Stein, Tait, Ferreirós, Shapiro and Clark and Demopoulos, among others, understand 'logicism' in significantly different ways. Hence a first task will be to fix what to me seems to be an accurate definition of the term 'logicism', at least in its original meaning. Then, I shall explain to what extent

\footnotetext{
${ }^{28}$ Stein $1988,239$.

${ }^{29}$ Hilbert 1905.

30 Tait 1993, 313.

${ }^{31}$ Tait translates Abbildung by function: "I am very sympathetic with the view that the notion of function is a logical notion: a warrant for $\forall x \varphi(x)$ must be a function assigning to each $b$ in the range of $x$ a warrant to $\varphi(b)$, and a warrant for a proposition $\mathrm{A} \rightarrow \mathrm{B}$ is a function that assigns to each warrant of $A$ a warrant of $B$. So the primitive truths of the logic of $\forall$ and $\rightarrow$ are truths about functions." $(1993,314)$.

${ }^{32}$ Ferreirós 1999, especially chap.VII.

${ }^{33}$ Ferreirós' "On Dedekind logicism", a copy of which I have recently read.
} 
Dedekind's contribution can be held as logicist in a loose sense. However, I will insist on fundamental differences with Frege. In my opinion, there was no Frege-Dedekind tradition at the time of those two authors' works. As a testimony of my claim I quote footnote 5 in the preface of $G g$ :

In vain do we seek notice of my Grundlagen der Arithmetik in the Jahrbuch über die Fortschritte der Mathematik. Researchers in the same area, Dedekind, Otto Stolz, von Helmholtz, seem not to be aware of my works. And Kronecker fails to mention them in his essays on the concept of number. ${ }^{34}$

Frege criticizes harshly Stolz, von Helmholtz, Kronecker, and Dedekind; he repeatedly strongly differentiates himself from them. Frege's own claim should be taken more into account, even if it remains true that Hilbert, Russell, Gödel, Tarski and their followers forged their own views partly by blending elements from Dedekind's and Frege's works. The blending happened and happens in so many ways that it may sometimes be difficult to discriminate what originally belonged to Dedekind and what belonged to Frege. Nonetheless we get more fine-featured information on Dedekind and on Frege by differentiating rather than unifying them under one and the same perspective. The least benefit from that may consist, for example, of avoiding a confusion between Dedekind's procedure for getting his 'abstract numbers' and what Russell calls the "principle of abstraction", i.e. with what we now call Hume's principle (HP). This last naming has the advantage not to use the 'word' abstraction, that Frege understands as Aristotelean abstraction and rejects as being a psychological process ${ }^{35}$, while he admits abstract objects as logical objects recognizable through a logical means, thus equating 'abstract' with 'logical'. Once made the distinction between Dedekind's process of abstraction and Frege's method of transforming an equivalence relation into an identity, one cannot merge Dedekind's "shadows-like forms" [schattenhafte Gestalten] with Frege's determinate cardinal numbers [bestimmte, angebbare Zahlen], which are individual self-subsistent logical objects ${ }^{36}$.

\footnotetext{
${ }^{34}$ It is well known that the publication in 1887 of Kronecker's "Über den Zhalbegriff" and of von Helmholtz's "Über Zählen und Messen" induced Dedekind to publish Z (Preface to the first edition) on which he had been working for a long time.

35 "There must be a sharp separation of the psychological from the logical, the subjective from the objective" is the first of the three fundamental principles of $G l$.

${ }^{36}$ As pointed out by Boolos $(1998,214)$ Frege's proof that every number has a successor depends on the assumption that numbers are objects. And it is only if one supposes numbers not to be objects that HP looks analytic or obvious.
} 
The rest of my study will be divided in four remaining parts: the second one will recall briefly the main features of Frege's logicism and Carnap's characterization of the logicist thesis. The third one will show in detail how by the same fundamental words such as 'logic', 'number', 'thought', 'pure thought', 'laws of thought, 'concept', 'object', and 'function', Dedekind and Frege express radically different conceptual views. The fourth part will be devoted to the status of definitions: Dedekind and Frege thought differently about this important issue. The fifth and last part will take stock of the meaning of the term 'concept' and it will reconsider the meaning of structuralism and logicism respectively, and I shall claim that these terms describe two related but distinct perspectives.

\section{The logicist thesis}

\subsection{The "new logic"}

Frege's work being considered as the very root of logicism, I shall leave aside, for the sake of clarity, Russell's changing over time elaboration ${ }^{37}$ of the logico-philosophical position upheld by Frege, at least up to the publication of the second volume of $G g$ (1903). Indeed, logicism originates from Frege's $B g$, while some traits are already in Leibniz' views. Frege's explicit goal is a "renewal of logic" 38 , which consists of 1) replacing the traditional Aristotelian splitting subject-predicate by the function-argument analysis, and 2) inventing a formal language appropriate for expressing the very logic of "pure thought" and the relations [Beziehungen] of concepts. Bg establishes a "formula language" of logic (which contains the essentials of first- and second-order quantification with identity) with specific symbols and definite rules ${ }^{39}$ according to which derivations are carried out exclusively by virtue of the "logical form" of expressions. The relations of concepts ${ }^{40}$ are analysed in terms of function-

${ }^{37}$ Concerning Russell's views see, e.g., Boolos 1998, chap.16, 18, 292.

${ }^{38} \mathrm{Gg}$ I, Preface, last sentence: "May my book, then, even if belatedly, contribute to a renewal of logic."

${ }^{39}$ Frege's formal language has two connectives, negation and the conditional, six axioms, the universal quantifier introduced in $\S 11$ under the name 'Generality' with three more axioms, and two rules: explicitly modus ponens and, implicitly, rule of substitution. Relations of concepts are ruled by logical inference; later (1891-92), Frege will hold that all relations between concepts can be reduced to the "fundamental logical relation of an object's falling under a concept". And if an object falls under a concept, it falls under all concepts with the same extension; then, "in relation to inference, and where the laws of logic are concerned, concepts differ only as so far their extensions are different." ("Comments on On Sinn and Bedeutung", Beaney 1997, 173).

${ }^{40}$ Concepts are predicates of judgements, like in Kant's Critic of the pure reason, Transc. Analyt. I, chap.1, but Frege sees predicates as mathematical functions. By contrast, Dedekind 
argument ${ }^{41}$ : "It is easy to see", writes Frege, "how taking a content as a function of an argument gives rise to concept formation"42. In part III, Frege presents a logical reconstruction of "a general theory of sequences" which offers a "further analysis of arithmetical concepts and a deeper foundation for arithmetical theorems". Such a formal system of logic, which allows purely logic derivations written down in a specific artificial language whose primitive symbols and primitive propositions are explicitly enunciated and whose rules of inference are listed from the start, constitutes the prerequisite for what Carnap calls "the new logic", by contrast with "the old logic" $" 43$, which was considered as "closed and completed" by Kant. In addition to Frege, Carnap counts Peano and Schröder as founders of "the new logic", and he recalls the chief work of Whitehead and Russell as the great fundament that all their successors have completed or reshaped. Carnap does not include Dedekind among the founders of "the new logic" $"$. Indeed, if one admits that, roughly, logicism is the thesis that mathematics can be reduced to formal logic, then the very first reason not to count Dedekind as a logicist is given by the term 'formal': Dedekind is not working in a formal language. Moreover, when Carnap brings up the reduction of the concepts of Analysis to arithmetical concepts and deals with the "logical analysis" of the concept of number ${ }^{45}$, he does not mention Dedekind's work at all. First, if "logical analysis" means the analysis of propositions into their logical constituents, which replaces the grammatical splitting predicate-subject with that of function-argument and extracts contentual information from the way of using words, as Frege proposes in $B g$ and $G l^{47}$, there is no doubt that Dedekind does not practise this kind of analysis. Nowhere Dedekind does try to characterize numbers by using number-words or making a judgement involving numbers. His

does not consider the notion of judgement, because he does not tackle the question of the truth.

${ }^{41}$ Later, in his essay "Function and concept", Frege will define a function as an "unsaturated expression" and introduce the notion of a values range as referring to a set of pairings of arguments with values.

${ }^{42} \mathrm{Bg}$, Preface.

${ }^{43}$ Carnap 1930.

${ }^{44}$ Carnap 1930, 14.

${ }^{45}$ Carnap 1930, 15 and $\S 6,20-21$.

${ }^{46}$ The expression is used by Frege, e.g. in "Logic in mathematics", presumed to be Frege's lecture notes of a course attended by Carnap in the spring of 1914.

47 "To throw light on the matter, it will help to consider number in the context of a judgement that brings its ordinary use." ( $G l \S 45)$. "What is the number itself?...We may try to know something about the number itself from the way of using the numerals and number-words. We use the number-words as names of objects, as proper names." (Frege 1979, 313). "In arithmetic a number makes its appearance in the singular as a proper name of an object of this science; it is not accompanied by the indefinite article, but is saturated." (Beaney 1997, 366). 
extension of the mathematical concept of function through his specific use of 'Abbildung' does not result from a logical analysis of the language of "pure thought". The ways Frege and Dedekind go from mathematical function to 'Begriff' and 'Abbildung' respectively show obviously two dissimilar ways of generalization: the first one substitutes mathematics for grammar in a logical analysis of language, taking the "linguistic turn" and introducing quantification, the second one is a mode of thinking presented as "logical" inasmuch as it applies everywhere in mathematics. However, if 'logical analysis' designates a work which takes place before construing a system, yields the primitive concepts and "articulate [their] sense clearly", as Frege states in "Logic in mathematics"48, then the letter to Keferstein (February 27, 1890) ${ }^{49}$ shows that Dedekind recognizes the necessity of "analysis" before the "synthesis", but his understanding of these operations is akin to the analysis/synthesis of the Ancient ${ }^{50}$ rather than to the Kantian division analytic vs synthetic judgements from which Frege starts in $G l$ and which he abandons later in $G g$ at the benefit of a more Euclidean view of analysis/synthesis.

The total absence of Dedekind in Carnap's picture leads us to reappraise the logicist interpretation of Dedekind's work on numbers and to wonder when it became, in retrospect, a banal issue in the philosophy of mathematics. Anyway, Dedekind's work does not meet the benchmarks set by Carnap for "the new logic": the symbolic formulation, primitive logical symbols and rules of inference being explicitly stated first ${ }^{51}$, the theory of relations (De Morgan and Peirce are mentioned as precursors), Russell's theory of types which allows the avoiding of the paradoxes ${ }^{52}$, the tautological or analytical character of all the logical, and consequently of all the mathematical propositions (generalization of Freges' view on the analytical character of arithmetical propositions) ${ }^{53}$.

I will take Carnap's characterization of logicism, which is up till now mainly and mostly taken on, as a basis for my further examination.

\footnotetext{
${ }^{48}$ Beaney 1997, 317-318.

${ }^{49}$ Van Heijenoort 1967, 98-103.

${ }^{50}$ See Sieg \& Schlimm 2005.

${ }^{51}$ Frege stresses that in $Z$ : “... an inventory of the logical or other laws taken by him as basic is nowhere to be found..." ( $G g$, Preface).

52 Symptomatically enough, Carnap does not refer to Zermelo's way of avoiding the paradoxes.

${ }^{53}$ Gödel distinguishes between 'tautological' and 'analytic' and points out that the elementary theory of integers is demonstrably non-analytic as a consequence of his incompleteness theorem $(1944,139$, fn 46).
} 


\subsection{Logicist foundations of mathematics}

In the introduction of $G l$, Frege claims that he will "make clear that even an inference like that from $n$ to $n+1$, which on the face of it is peculiar to mathematics, is based on the general laws of logic". A claim that was already grounded on, and justified by his results in $B g$, section III, where the mathematical induction appears as a special case of the logical relation that Whitehead and Russell named "the ancestral relation" $" 54$. So mathematical induction is a species of logical inference. In $G l \S 87$, Frege is less affirmative. He writes that he has only the "hope" that his $G l$ "have made probable that the laws of arithmetic are analytic judgements and consequently a priori. Arithmetic thus becomes simply a development of logic, and every proposition of arithmetic a law of logic, albeit a derivative one" ${ }^{\natural 5}$. Later on, Frege provides us with what he thinks to be a confirmation of this hope. Indeed, in $G g \S 0$, he asserts: "In my Grundlagen der Arithmetik, I sought to make it plausible that arithmetic is a branch of logic and need not borrow any ground of proof whatever from either experience or intuition. In the present book, this shall be confirmed by the derivations of the simplest laws of numbers by logical means alone.” But the problem with basic law V soon appears and the question arises the question whether the logicist programme can be fulfilled. I do not want to address this question, nor to consider the solutions proposed by Frege, by Russell, and by the modern supporters of neo-logicism. I am rather limiting myself to recall what is generally taken to be the logicist programme in terms of Carnap's twofold characterization, which up till now is mostly endorsed. Indeed, in Carnap 1931 two requirements are enunciated.

1) "The concepts of mathematics can be derived from logical concepts through explicit definitions."

After an outline of the logical material necessary and sufficient (predicate calculus with identity) for deriving natural numbers from logical concepts, Carnap quotes Frege's definition of whole numbers as "logical attributes which belong to concepts", and he mentions Russell's and Whitehead's work which corroborates "the logical status of the natural numbers". Then, Carnap considers the derivation of the other kinds of numbers, and only then he briefly exposes Dedekind's cuts - and not Frege's conception of real numbers, which is based on the

${ }^{54}$ Frege's formulation in $B g$ \$26 is: "If from the two propositions that every result of an application of the procedure $f$ to $x$ has property $F$ and that property $F$ is hereditary in the $f$ sequence, it can be inferred, whatever $F$ may be, that $y$ has property $F$, then I say: " $y$ follows $x$ in the $f$-sequence", or " $x$ precedes $y$ in the $f$-sequence"."

${ }^{55}$ Also $G l$ §109: "From all the preceding it thus emerged as a very probable conclusion that the truths of arithmetic are analytic and a priori; and we achieved an improvement on Kant's view." 
concepts of magnitude, measure and ratio - before passing to Russell's own remodelling of Dedekind's definition of real numbers through cuts. Carnap indicates that this process runs up against the problem of impredicative definitions. And he insists on the fact that "the logicist does not establish the existence of structures which have the properties of the real numbers by laying down axioms or postulates; rather, through explicit definitions, he produces logical constructions that have, by virtue of these definitions, the usual properties of the real numbers" $"$. And he adds "As there are no "creative definitions" but only name-giving to something whose existence has already been established".

According to Frege indeed, the real task is not making postulates (or axioms or "formal definitions"), but showing that they are satisfied. In other words, freedom of contradiction in a concept is not a sufficient guarantee that something falls under it ${ }^{58}$. "The fundamental logical relation is indeed that of an object's falling under a concept: all relations between concepts can be reduced to this" ${ }^{\prime 59}$. Now, defining is fixing, determining what is named by a name or designated [bezeichnet] by a sign. Frege holds that a name is the name of an object and that a definition lays down what a sign/word expresses, i.e. it determinates univocally the conceptual content of the sign/word. Thus, concerning the cardinal numbers, such as $1,2,6$, etc., "it is not a matter simply of giving names, but of designating for itself the numerical content" ${ }^{\prime 60}$. It will appear to Frege, in the 1890 's ${ }^{61}$, that 'the conceptual content' is twofold; it is 'Sinn' (sense) and 'Bedeutung, ${ }^{62}$. In Gg Frege insists again on "the leading principle" according to which "alle rechtmäßig gebildeten Zeichen etwas bedeuten sollen"63. A definition indicates the connexion between a sign and what it designates [Zusammenhang

\footnotetext{
${ }^{56}$ My italics. Carnap opposes explicit definitions to axioms, though none of these wordings is present in $G l$.

${ }^{57}$ About Frege's discussion of "Die schöpferischen Definitionen” see $G g$ §§139-147.

${ }^{58} \mathrm{Gl} \S 109$; Gg II §86: here Frege contrasts between "die formale Arithmetik (Heine, Thomae) und die inhaltliche Arithmetik"; Gg II, §§139-147. See also Frege/Hilbert correspondence in Frege 1967.

${ }^{59}$ Frege insists that this relation of subsumption is distinct from the relation of inclusion.

${ }^{60} \mathrm{Gl} \S 28$. In $\S 43$, Frege criticizes Schröder's supposed assimilation of the number with a sign. $B g$ was designed for expressing the "conceptual content" [den begrifflichen Inhalt], which is independent from the peculiar proposition which expresses it.

${ }^{61}$ Letter to Husserl 1891, Beaney 1997, 149-150. "On Sense and Bedeutung" (1892), Beaney 1997, 151-171. "Comments on On Sense and Bedeutung", Beaney 1997, 172-180.

${ }^{62}$ The sense of a sentence is a thought; its Bedeutung is its truth-value. And judgement "could be characterized as a transition from a thought to a truth-value.", Letter to Husserl 1891, Beaney 1997, 150. On Sense and Bedeutung, Beaney 1997, 151-171.

${ }^{63} \mathrm{Gg}$ Preface and $\S 28$.
} 
zwischen Zeichen und Bezeichnetem]. By a definition "something ${ }^{64}$ is marked out in sharp relief and designated by a name". Thus "formal definitions", in which one rests content with introducing signs without making a link with some object, be it concrete or abstract - senses and Bedeutungen are abstract objects - are not accepted. Notice that in Frege's view definitions by axioms are not necessarily "formal definitions"; in fact, according to Frege, they are not definitions at all.

Carnap stresses the "constructivistic" character of Frege's conception of definitions and claims that "a constructivistic" method forms part of the very texture of logicism" 65 . He makes a link with intuitionism. However, 1) Frege's constructive definitions do not result from a construction of the mind, based on the a priori insight of time - as claims Brouwer. They are grounded on timeless logical objects and logical methods of inference. 2) Frege does not subscribe to the algorithmic constructivism vindicated by Kronecker, who holds that the positive whole numbers are given by God and, consequently, need no definition. We shall see below (IV.2.) what Frege means exactly by the expression 'constructive definition' [aufbauende Definition] employed in 1914.

As to Dedekind there is no more comment in Carnap's paper. Nevertheless we know that Dedekind holds that creating new mathematical concepts is more than fruitful ${ }^{66}$ and he is used to laying down a small number of necessary and sufficient conditions (NSC) as the explicit starting point of his deductions. These NSC are taken as definitions as show $Z 71,73$. We know also that Dedekind clearly rejects the constructivistic standards as contrary to actual infinities, especially Kronecker's "limitations upon the free formation of concepts [Begriffsbildung] in mathematics"67.

2) The second claim of logicism is that "the theorems of mathematics can be derived from logical axioms through purely logical deduction."

Carnap comments on 2) as meaning that "every provable mathematical sentence is translatable into a sentence which contains only primitive logical symbols and which is provable in logic". 'Translation' does not match Frege's view that true arithmetic propositions

\footnotetext{
${ }^{64}$ My italics.

${ }^{65}$ Carnap 1931, 34.

${ }^{66} Z$, Preface to the first edition.

${ }^{67} Z$ §I.1, footnote. Frege also employs in Bg, Preface, the term 'Begriffsbildung', which was common at that time. But while Dedekind aims at creating new specific mathematical concepts, Frege aims at showing the general logical method grounding the uniform process of concept formation.

${ }^{68}$ Carnap 1931, 41.
} 
are derivable from purely logical laws provided that the logical definition of the concept of number is stated. But Frege's view clashes with Gödel's first incompleteness theorem.

Boolos calls 1) and 2) respectively the definability thesis and the provability thesis of logicism". ${ }^{69} \mathrm{He}$ draws attention to a supplementary distinction, that must hold between propositions which can be expressed in the language of pure logic and propositions true by virtue of logic alone. A proposition assumed to be true and expressed in logical terms is not necessary a logical truth. Russell noticed with the example of the axiom of infinity, that "though it can be enunciated in logical terms, it cannot be asserted by logic to be true" Parsons notes that, since the structure of natural numbers is second-order definable, "the simple translation of the language of arithmetic into that of second-order logic has been offered as a basis for a defense of the view that arithmetic is a part of logic"71, giving birth to a "logicist eliminative program" illustrated by Putnam's if-thenism (1967b) and by Putnam's and Hodes' recourse to modal notions instead of abstract objects such as sets and numbers ${ }^{72}$. According to Parsons, for logicism proper it's not sufficient to exhibit a mapping which translates all arithmetic truths into logical truths ${ }^{73}$. Hence Boolos' distinction between truths of logic and truths expressed in the language of logic ${ }^{74}$. Boolos adds that the definability thesis alone does not suffice to show the truths of mathematics to be logical truths and no one "counts as a full-fledged logicist who does not endorse the provability thesis as well as the definability thesis"75. By the yardstick of a "full-fledged logicism", at which Frege aims, Dedekind is definitely not a logicist. Yet I have to explain why he has been or might be interpreted as advocating a kind of logicism. Before proceeding some words more on Carnap's views.

Carnap displays the difficulties of the logicist programme, in particular in the treatment of the real numbers. He mentions Ramsey's solution: accepting impredicative definitions with the presupposition that the totality of properties already exists before their definition. This

\footnotetext{
${ }^{69}$ Boolos 1998, 270. For a more refined distinction between language-logicism, consequencelogicism and truth-logicism, see Rayo 2005: Frege's project was truth-logicism as far as mathematical truths can be proved merely "on the basis of general logic laws and definitions". ${ }^{70}$ Russell 1919.

${ }^{71}$ Parsons 1990, $312 \mathrm{ff}$.

${ }^{72}$ Putnam 1967a, Hodes 1984.

${ }^{73}$ Anyway, such a mapping cannot exist since arithmetic is undecidable (Boolos 1998, 208).

${ }^{74}$ Boolos 1998, 211.

${ }^{75}$ Boolos makes this remark in order to state that Russell advocates the definability thesis but not the provability thesis (1998, chap.16).
} 
conception is akin to the "belief in a platonic realm of ideas which exist in themselves, independently of if and how finite human beings are able to think them". Thus the logical structure of the purposed system involves or might involve a philosophical stand on the nature of the things designated by the signs or singled out by the definitions of that system. Carnap thinks 1) that Frege does not share this belief in "theological mathematics", since for him "only that may be taken to exist whose existence has been proved",76; 2) that Ramsey's solution can be accepted without falling in his "conceptual absolutism". Leaving aside Ramsey's conception and Carnap's empiricist fighting against the conceptual absolutism, I shall focus on Frege's clearly asserted philosophical assumptions and compare them, at least on some crucial points, with Dedekind's less systematically developed views.

\section{Similar claims, different fundamental conceptions}

In this part I should recall first that Frege has more or less strongly changed his mind ${ }^{77}$ over time about such fundamental issues as the logical status of cardinal numbers and their identification with extensions of concepts, the distinction between aggregates and extensions, the sharp distinction between arithmetic and geometry, the sharing out of mathematical propositions into synthetic and arithmetic propositions, the division between a priori and empirical truths, the uselessness or the need of intuition in the deductive development of arithmetic, the radical difference between, on the one hand, definitions that fix definitely the sense of the signs used or introduced and that determinate for all time the objects to which mathematical propositions refer and, on the other hand, the so-called creative definitions that single out a few primitive propositions from which theorems can be derived. If we also take

\footnotetext{
${ }^{76}$ This is Carnap's biased rephrasing of Frege's following statements: "In mathematics a mere moral conviction, supported by a mass of successful applications, is not good enough. Proof is now demanded for many things that formerly passed as self-evident...In all directions the same ideals have be seen at work - rigour of proof, precise delimitations of extent of validity, and as a means to this, sharp definitions of concepts." ( $G l \S 1)$. Nevertheless Frege assumes that abstract objects, such as thoughts or senses or numbers or mathematical truths, have a changeless existence, different from that of the real [wirklich] world and that of the inner world of an experiencing subject.

${ }^{77}$ Bynum 1976 stresses that in $G l$ Frege "expressed discomfort with the identification of numbers with extensions", a discomfort that pushed him to deal with that part of logic, the "fundamental logic", that is independent of set-theory. Hodes (1984, 143-144) points out the difficulty in interpreting Frege's Diary Notes on number (Frege 1979, 263-266). According to Dummett Frege's early writings do not contain "a complete systematic theory of philosophical logic comparable to, and in competition with, that propounded by him from 1891 onwards." (Dummett 1991, 161). Parsons 1976 shows how Frege came to reject extensions as being really objects along with logicism.
} 
into account the fact that Frege's final views conflict with his first beliefs, sometimes straight out, plus the fact that HP turned out to be a consistent but not purely logical (purely analytical) proposition, we will agree wholeheartedly with Boolos' conclusion according to which Frege himself was not a logicist in the strict meaning of the word. Nevertheless, there is actually a set of claims that are thought to be characteristic of the logicist project, on which many outstanding scholars are still working. The main claim is that $\mathrm{FA}=\mathrm{HP}+$ second-order logic makes a consistent system which allows for interpretations as arithmetic ${ }^{78}$. Then the double question will be: 1) is Dedekind's characterization of the natural numbers and of the real numbers a planned, if not a successful, logicist reduction, i.e. are numbers logical objects? 2) Does Dedekind believe that thoughts or truths are subsisting by themselves? The difficulty with Dedekind is not so much that he changed his mind - as happens to any thinker -, but rather that he was more involved in mathematical practice than in philosophical or logical investigations. Therefore, the scattered remarks of a philosophical or logical nature, that he made in $S, Z$, the letters to Lipschitz, to Keferstein, to Weber, and in some other rare places, have to be embedded in his mathematical writings.

Nevertheless, I can expound Dedekind's and Frege's dissenting opinions about the dichotomy reason/intuition (3.1.), about the meaning of 'thought', 'law of thought', 'logic' and 'proof' (3.2.1 to 3.2.5.), and about 'truth' (3.3.).

\subsection{Reason versus intuition, foundations of arithmetic}

As is well known, the impulse to the search for rigour in the second half of the nineteenth century was the arithmetization of infinitesimal analysis. As Dedekind puts it, endorsing Dirichlet's view, "every theorem of algebra and higher analysis, no matter how remote, can be expressed as a theorem about natural numbers",79. Therefore the task is to give a "real definition" (Frege) or to single out a few essential or "inner" properties (Dedekind) of the natural numbers. Both Frege and Dedekind vindicate the autonomy of arithmetic vis-à-vis any intuition and experience in Kant's sense and take Kant's transcendental aesthetics as a target for their criticisms. Dedekind thinks that mathematics does not proceed by construction of concepts into intuition, and that mathematical theories do not develop out of observation of facts nor of any apprehension of spatiotemporal data. Reason, or "pure thought", alone is at

\footnotetext{
${ }^{78}$ The claim that every arithmetic truth is a theorem of the system is abandoned because it clashes with Gödel's first incompleteness theorem.

${ }^{79} Z$, Preface to the first edition.
} 
work not only in arithmetic - as holds Frege ${ }^{80}$, but also in the whole body of pure mathematics. Even though Dedekind takes on Gauß' view on the priority of arithmetic over geometry and affirms the autonomy of the former from the latter, he, contrary to Frege ${ }^{81}$, does not endorse the opinion that geometry is rooted in intuition. According to his innovative views, there is no epistemological difference between arithmetic and geometry; as a deductive science geometry is shaped in a similar way as arithmetic. And the Cartesian correspondence between curves and equations shows the common structure between real numbers and real functions of real variables. Moreover, for Dedekind arithmetic means the whole body of numbers, be they natural numbers or negative or rational or irrational or complex numbers. Dedekind's goal is to achieve in a uniform way the gradual numerical extension of natural numbers without any help of any non-numerical notion ${ }^{82}$, in particular without appeal to geometrical notions or to the notion of measurable magnitude. One determines a measure by a number, not the other way round.

In $G l$ Frege agrees with that ${ }^{83}$; but in $G l$, Frege's concern is solely the logical reduction of cardinal numbers. This option is confirmed in the first volume of $G g^{84}$. However, already in $G l$, Frege claims that "with the definition of fractions, complex numbers and the rest, everything will in the end come down to the search for a judgeable content which can be transformed into an identity whose sides precisely are the new numbers. In other words, what we must do is fix the sense of a recognition-judgement for the case of these numbers... then the new numbers are given to us as extensions of concepts" ${ }^{\prime \prime}$, and not as successive numerical extensions out of the natural numbers. In the second volume of $G g$, Frege still rejects "das

${ }^{80}$ Gl §105: "We are concerned in arithmetic not with objects that become known to us through the medium of the senses as something foreign from outside, but with objects that are immediately given to reason, which can fully comprehend them, as its own." (Beaney 1997, 126).

81 "In geometry it is quite intelligible that general propositions should be derived from intuition" ( $G l \S 13)$; "Everything geometrical must surely originate in intuition" ( $G l \S 64)$.

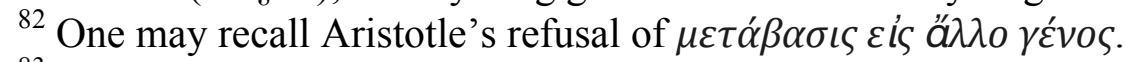

${ }^{83}$ In arithmetic Frege "should like straight away to oppose the attempt to think of number geometrically, as a ratio between lengths or surfaces." ( $G l \S 19)$.

84 "It will be seen that negative, fractional, irrational, and complex numbers have still been left out of account, as have addition, multiplication, and so on." (Preface)

${ }^{85} \mathrm{Gl} \S 104$. Extensions of concepts are objects (the reverse being false); they amount to sets, naively conceived. But Frege's interest on extensions roots in concerns of general logic not of sets (On Schönflies, Frege 1979, 183: "The extension of a concept simply has its being in the concept, not in the objects which belong to it; these are not its parts." "A relation of a part to the aggregate must still always be distinguished from that of an object to the extension of the concept to which it belongs".) 
stückweise Definieren" ${ }^{\wedge 6}$, for instance the definition of real numbers out of rational numbers alone - as Dedekind does in $S$-, and he distinguishes as two completely separated domains the cardinal numbers, which answer the question: "How many?", and the real numbers, that he calls measure-numbers [Maßzahlen], since they are used in measuring continuous magnitudes ${ }^{87}$. Frege uses 'irrational number' and 'real number' as expressing a "Größenverhältnis". But one must not reduce the measure-numbers to geometry: "Größenverhältnis" does not mean ratio between lengths or surfaces. As a measure-number a real number indeed applies to different kinds of continuous magnitude: geometrical magnitudes, but also temperature, time-interval, maß, etc. Such an abstract concept of magnitude is already present in Euclid, book V, and it is applied to geometry in book VI and to arithmetic in book VII, but Euclid did not aim at grounding the concept of number on that of ratio of magnitudes, since for him 'number' means only positive whole numbers $\geq 2$. By contrast, Frege claims that the abstract concept of magnitude belongs to arithmetic ${ }^{88}$, just it does not result from successive extensions of the cardinal numbers ${ }^{89}$; it needs a definition of its own. As Größenverhältnis a real number is not itself the measured magnitude; it is the measure of the relation [Beziehung] of some element of a class of magnitudes to a distinguished element chosen as a unit. Finally, a real number is an extension of a relation called a Relation - between extensions of relations, i.e. between Relations ${ }^{90}$. A domain of magnitudes is a class of extensions of relations, a class of Relations. What matters is that the notion of relation is treated as a purely logical notion; the extension of a relation is also thought of as purely logical; Frege thinks that he is implementing in $G g$ for the real numbers the logical reduction made in $G l$ for cardinal numbers - but Frege's extensions clash with Russell's paradox. It has been noted that Frege's treatment of real numbers contains valuable insights into what would later be developed as groups with orderings ${ }^{91}$, but in that line of thinking Dedekind has priority since he takes in $S$ (and even earlier) the fundamental steps for considering algebraic ordered structures, especially ordered groups and ordered fields. Defining the real numbers (up to isomorphism) out of rational numbers alone is extending the algebraic totally ordered structure of the field $\mathbf{Q}$ to the field $\mathbf{R}$ or, in modern terms, embedding

\footnotetext{
${ }^{86} \mathrm{Gg}$ II §57; also "Logic in mathematics”, Frege 1979, $242 \mathrm{ff}$.

${ }^{87} \mathrm{Gg}$ II $\$ 157$.

${ }^{88} \mathrm{Gg}$ II $\$ 158$.

89 "Es [ist] nicht möglich, das Gebiet der Anzahlen zu dem der reellen Zahlen zu erweitern; es sind eben ganz getrennte Gebiete".

${ }^{90} \mathrm{Gg}$ II $\S 162$.

${ }^{91}$ Dummett 1991, 53-64.
} 
$\mathbf{Q}$ in $\mathbf{R}$, then identifying $\mathbf{Q}$ with its image in $\mathbf{R}$, and this identification constitutes a step inconceivable in Frege's frame ${ }^{92}$.

In the final year of his life Frege comes back to Kant's epistemology and writes: "An a priori mode of cognition must be involved [in the sequence of whole numbers]. But this cognition does not have to flow from purely logical laws, as I originally assumed.... The more I have thought the matter over, the more convinced I have become that arithmetic and geometry have developed on the same basis - a geometrical one in fact - so that mathematics in its entirety is really geometry" ${ }^{\prime 93}$. Frege is here again at odds with Dedekind's constant view that arithmetic is the root of mathematics and that any branch of mathematics, even geometry, is a purely deductive science in the sense that it singles out the primitive propositions expressing the essential properties on the basis of which (possibly) all the theorems of the science could be proved. For Dedekind even in the science of space intuition is misleading and useless: Dedekind is the first mathematician who states that "continuity" (connectedness) is not given to us by spatial intuition; according to him, we do not have really a visual or intuitive apprehension of the continuity of a geometric line drawn on the blackboard, we conceive of $\mathrm{it}^{94}$ as a property that "we attribute to the line" (or to space) by a convenient axiom, which must be explicitly formulated as a primitive - non provable - principle ${ }^{95}$, since "for a great part of the science of space the continuity of its configurations is not even a necessary condition" $"$. Thus the continuity principle is not necessarily true in any geometrical space; it is not a logically true principle valid in any space, even less in any System of elements. Moreover, "even if we knew for certain that space was discontinuous there would be nothing to prevent us, in case we so desired, from filling up its gaps, in thought, and thus making it continuous" 97 . A mathematical space is a thought-entity; the distinction between arithmetic and geometry comes down not to the division between concept (or relation in Frege's sense)

\footnotetext{
${ }^{92}$ Such identifications are very usual in mathematical practice, but the philosophical question about how to conceive of, e.g., the identity of 2-rational and 2-real gives still rise to subtle discussions.

93 "Numbers and arithmetic", Beaney 1997, 373. And also "A new attempt at a foundation of arithmetic": "I have to abandon the view that arithmetic does not need to appeal to intuition either in its proofs, understanding by intuition the geometrical source of knowledge, that is, the source from which flow the axioms of geometry"; the logical source of knowledge "on its own cannot yield us any objects" ... and it "probably cannot yield numbers either", Frege 1979, 278, 279.

${ }^{94} S \S 3$

${ }^{95} S \S 5.3$.

${ }^{96} Z$, Preface to the first edition.

${ }^{97} S \S 3$ (my italics).
} 
and intuition ${ }^{98}$, but to the distinction between two mathematical concepts: that of number $\left[Z a h l^{99}\right]$ and that of magnitude [Größe], and in particular that of real number and that of continuous magnitude, the former being independent from the latter. For Dedekind real numbers are as much numbers as natural numbers ${ }^{100}$ and if we wanted to define numbers as the result of measuring a magnitude by another of the same kind [gleichartige], we would fail in the case of complex numbers. Then "arithmetic must develop itself out of itself"101, assuming the radical difference between number and magnitude, not between natural and real numbers. When Dedekind writes in $Z$ (1888) - nothing like this is to be found already in $S$ (1872) - that arithmetic, algebra and analysis are "a part of logic", that means 1) that they are "totally independent from the intuitions of space and time"102, 2) hence, that the concept of number "flows immediately from the pure laws of thought", what, in Dedekind's view, means that numbers together with numerical operations ${ }^{103}$ are rooted in the constitution of the mind or, as Dedekind writes to Keferstein (February 27, 1890), they are "subsumed under more general notions and under activities ${ }^{104}$ of the understanding [Verstand] without ${ }^{105}$ which no thinking is possible", and 3) that "the numbers are free creations of the human mind [menschlicher Geist]", so that the entire number-domain, from natural to complex numbers, is

${ }^{98}$ In $G l \S 13$, Frege holds that points, lines and plane are not individuated as are the numbers.

99 Dedekind uses 'Zahl' or 'natürliche Zahl' with the meaning of finite 'Ordinalzahl' ( $Z$, Definition 73); he has the same use as Frege ( $G l, \S 4)$ for 'Anzahl' (Z, Definition 161): 'cardinal number'.

${ }^{100}$ Naturally, they don't have the same structure, even though the totally ordered semi-ring of natural numbers is embedded in the totally ordered field of real numbers.

${ }^{101} S \S 3$.

102 "In speaking of arithmetic (algebra, analysis) as a part of logic I mean to imply that I consider the number-concept entirely independent of the notions of intuitions of space and time, that I consider it an immediate flow from the laws of pure thought." ( $Z$, Preface to the first edition, notice that Dedekind does not write "the laws of logic", but "the laws of thought").

${ }^{103}$ See, e.g., $S$ 1: "I regard the whole of arithmetic as a necessary, or at least natural, consequence of the simplest arithmetic act, that of counting, and counting itself as nothing else than the successive creation of the infinite sequence of positive integers in which each individual is defined by the one immediately preceding... The chain of these numbers forms in itself an exceedingly useful instrument for the human mind; it presents an inexhaustible wealth of remarkable laws obtained by the introduction of the four fundamental operations of arithmetic. Addition is the combination of any arbitrary repetition of the above-mentioned act into a singular act..." (my italics).

${ }^{104}$ My italics. In a famous letter to Bessel (April 9, 1830), Gauß writes that "the number is a pure product of our mind" (quoted in Dugac 1976, 40). And in a fragment of 1882, Dedekind maintains that "Analysis in its entirety is a necessary consequence of the thought as such" (Dugac 1976, 199).

${ }^{105}$ Dedekind's italics. 
"created in our mind". In Frege's view 1) holds at least from the time of $B g$ to that of $G g$, the last posthumous writings on number being excluded; 2) holds only if one understands 'thought' and 'the laws of thought' in a way significantly different from Dedekind's understanding - as it will appear more clearly below; 3) certainly does not hold at all: being derivable from purely logical concepts, or even from a geometrical source as in Frege's final texts $^{106}$, is incompatible, according to Frege, with being created by or in our mind or with being an "object of our thinking" [Gegenstand unseres Denken] as Dedekind says of any mathematical thing in general ${ }^{107}$. Whoever is familiar with Dedekind's writings knows that an "object of our thinking" is not really an object, but a concept, 'concept' being understood in the context of mathematical practice: mathematical progress comes from new concepts such as System, group, cut, chain, field, module, ideal, lattice, etc. - About Dedekind's and Frege's different conceptions of 'concept' see part 5.1.-

\subsection{Pure thought, objectivity, logic, proof}

\subsubsection{The laws of thought.}

The expression 'the laws of thought' is used by Frege ${ }^{108}$ and by Dedekind and for both of them this means the laws of the $e^{109}$ mind. Dedekind and Frege take thoughts as objective, and, following Kant, they both agree on understanding 'objective' as 'based on reason' ${ }^{110}$. But Frege goes one step further and repudiates the Kantian division between things in themselves and phenomena: he understands objective to be something whose 1) existence and 2) apprehension do not depend on our sensation, intuition, ideation or any "result of a mental

\footnotetext{
${ }^{106}$ Frege 1979, 274, 277.

${ }^{107} Z 1.1$

${ }^{108} \mathrm{Bg}$, Preface: "The firmest proof is obviously the purely logical, which, prescinding from the particularity of things, is based solely on the laws on which all knowledge rests....I first had to see how far one could get in arithmetic by inferences alone, supported only by the laws of thought that transcend all particulars" (Beaney 1997, 48). And $G l$, Introduction: "Thought is essentially the same everywhere. It is not the case that there are different kinds of laws of thought depending on the object [of thought]" (Beaney 1997, 86).

109 "Pure thought" is independent from any intuition of space or time and "solely from the content that results from its own constitution, bring forth judgments that at first sight appear to be possible only on the basis of some intuition." (Bg, Introduction, §23). "Thought", Beaney 1997, 342: "Neither logic nor mathematics has the task of investigating minds and contents of consciousness owned by individual men. Their task could perhaps be represented rather as the investigation of the mind; of the mind, not of minds". Dedekind would completely agree with this assertion.

${ }^{110} G l \S \S 26,27$ : "What is objective is what is law-governed, conceivable and judgeable, expressible in words."
} 
process" 111 . But, only the apprehension, not the existence, of what is objective depends on reason, while for Dedekind apprehension and existence depend on reason, since 'objective' means constitutive of the rational activity of the mind: 'activity' does not mean 'subjectivity'; it means that the objects of our thinking are not external to the thinking. Thus, for Frege, arithmetical objects are "immediately given to reason", 'immediately' having the sense of 'needing no mediation of the senses ${ }^{112}$, while Dedekind holds that natural numbers are not immediately given to reason but that they "flow immediately from the pure laws of thought". One word makes the difference ${ }^{113}$.

Frege remarks that "although mathematics, like all sciences, issues in thoughts, thoughts are not among the objects that it studies"114. That points out sharply the difference between mathematicians' and logicians' stands. No further comment is needed to stress that while the concepts and objects considered wear the same names they are treated from significantly different points of view by Dedekind and by Frege respectively.

\subsubsection{The laws of logic}

Frege frequently uses with the same meaning the expressions 'the laws of thought' and 'the laws of logic" or "the general laws of logic", and he comes to prefer the latter expressions, for they mean unambiguously that logic is not concerned with what one holds to be true, but with what is true. ${ }^{115}$ Now the expression 'laws of logic' is to be found nowhere in $S$ or $Z$. We find there the term 'logic' and 'logical' qualifying a foundation which rests upon more general and more primitive concepts than the concepts usually taken as primitive in arithmetic or analysis. Thus the concept of the numerical real domain comes first; on it depend the notions of limit, continuity or convergence of a real function of real variables ${ }^{116}$; hence the logical priority of arithmetic vis-à-vis geometry does not mean, as Frege holds, that geometry depends on

${ }^{111} \mathrm{Gl}$ §26. See Dummett's comments in Dummett 1991, 123-125.

112 Gl §105; Gg II, §74: "die logische Gegenstände sind nicht wirklich, aber darum nicht minder objectiv; sie können zwar nicht auf unsere Sinne wirken, aber durch unsere logische Fähigkeiten erfaßt werden. Solche logische Gegenstände sind unsere Anzahlen; und es ist wahrscheinlich, daß auch die übrigen Zahlen dazu gehören".

${ }^{113}$ Frege's assertion that "the validity of Dedekind's proofs [in $Z$ 66] rests on the assumption that thoughts obtain independently of our thinking" (Frege 1979, 136, footnote) does not hold: Dedekind takes thoughts to be objective but not to obtain independently of our thinking. Actually, Dedekind's thoughts-world does not exist independently of our thinking.

114 “Über die Grundlagen der Geometrie", quoted after Dummett 1991, 213.

115 "Logic", Beaney I997, 248-250.

116 Indeed, $S$ shows that the Dedekindian "completeness" of the real numbers field implies logically its Cauchy's completeness, once one defines a distance (a metric) on the field. 
intuition $^{117}$, it simply means, as Frege maintains too in his early period, that numbers and numerical operations have an intrinsic definition, with no appeal to geometrical notion. According to Dedekind, "logic" also allows for showing that the continuity of line and space neither is an explicit or implicit assumption among Euclid's definitions, axioms or postulates nor can be logically derived from them. Furthermore, "logic" allows to be shown that one can "establish with rigorous logic the science of numbers" upon "the definition of the infinite"118, i.e. that one can conceive of natural numbers as definable in terms of a "similar Abbildung" (injective function) on an infinite domain of abstract, i.e. non interpreted, elements. Dedekind deals also with logical dependence or independence, not with logical laws ruling the dependence relation. Moreover, in Dedekind's view, the most fundamental law of thought, the law which provides "the unique and therefore absolutely indispensable foundation ... [for] the whole science of numbers" is "the ability of the mind to relate things to things, to let a thing correspond to a thing, or to represent a thing by a thing, an ability without which no thinking is possible"119. The most fundamental law of thought is also the Abbilden-ability.

Correspondingly Frege holds that thoughts have to be analysed into function-argument. Yet the perspective opened by the Abbilden-ability is very different from the perspective opened by the function-argument analysis: the traditional concept of function is generalized in totally different ways and for different purposes. In the first case, the Abbilden-ability is a dynamic rational process resulting into mathematical innovations and progress, because it permits taking one thing for another playing the same role. What matters is not about identity but about analogy, which can hold across different domains. In the second case, the functionargument analysis affords a static frame for decomposing thoughts into their logical constituents in order to find out their truth-value. Frege's notion of function is our notion of logical predicate with one, two or more places; Frege's notion of generality is our universal quantification; for Frege the laws of thought are the laws of logic, and the laws of logic are the laws of truth.

\subsubsection{Thought and truth}

${ }^{117}$ Dedekind does not put an exclusive disjunction between logic and geometry, as does Frege in his early writings. He holds that the mathematical general concept of space differs from the Euclidean space, taken as intuitive until the nineteenth century, and from the physical sensible space.

${ }^{118} Z$, Preface to the second edition (my italics).

$119 Z$, Preface to the first edition (my italics): 'numbers' are not restricted to the natural numbers, they mean any kind of numbers. 
For Frege 'thought' has indeed a special meaning: a thought is "something for which the question of truth can arise at all"; thus thoughts are objects of logic, they fall outside the realm of mathematics proper as well as the head-on study of truth in and for itself. Frege explains that the laws of thought are the normative laws of logic and that there is no need for specific laws for arithmetic, for "aggregative thought" as he calls $i^{120}$. The laws of logic are the laws of being true not of being taken to be true, the laws of thought are not the laws of thinking. ${ }^{121}$ Thus, logic is not only the theory of inference but also the theory of truth, whose tools are judgement and concepts ${ }^{122}$. By contrast, Dedekind does not consider truth as the task of logic but as the goal of human scientific activity, and he believes that "arithmetizing"123, as he calls it, is a fundamental activity of human reason, which is applied to empirical tasks, but whose laws of operating are neither rooted in nor grounded on the experience. It is mostly with respect to this rejection of experience and intuition as being the basis that the laws of arithmetic are "a part of logic".

\subsubsection{Logicality}

Following Boolos, let us recall that logicality has three aspects:

1) logicality of proving: in arithmetic the chains of inferences by which one goes from principles to consequences must convey no ingredient foreign to arithmetic, in particular no intuitive or geometric ingredient, and must be logically free of gaps; that leads to three demands: a) making explicit the principles and excluding any tacit assumption, b) listing the rules of inference that will be used, and c) showing that any transition in a chain of inferences can be analysed into simple deductive/logical steps;

${ }^{120} \mathrm{Gl}$, Introduction, Beaney's $1997,86$.

121 "Logic", Beaney 1997, 248; “Thought”, Beaney 1997, 325-326: "I assign to logic the task of discovering the laws of truth, not the laws of taking things to be true or of thinking.".

122 The notions of judegment and concept are taken on from "the old logic" in general and, in particular, from Kant, but Frege's 'concept' is idiosyncratic and Frege's way of connecting concepts and judgements with the notion of truth is totally new. More precisely, Frege holds that "the theory of concepts and of judgement is only preparatory to the theory of inference", and that "the task of logic is to set up laws according to which a judgement is justified by others, irrespective of whether they are themselves true"; thus " the laws of logic can guarantee the truth of a judgement only insofar as our original grounds for making it, reside in judgements that are true."("Key sentences on logic"/ $\approx 1906$, Frege 1979, 175, 14., 15., and 16.). Boolos $(1998,333)$ points out that the following question may have occurred to Frege: "Can the notion of a truth of logic be explained otherwise than via the notion of provability?". Having not the notion of interpretation, Frege could not get the notion of logical consequence.

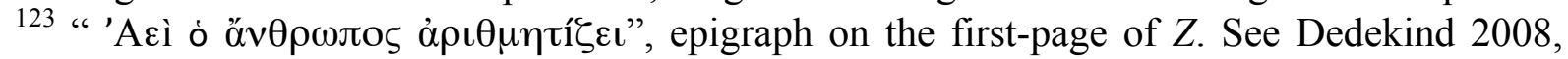
Introductory Note. It seems to me wrong to interpret the whole essay $Z$ as a "transcendental deduction" in Kant's specific sense (Mc Carty 1995) or to cut radically any link between Kant and Dedekind (Reck 2003). 
2) logical nature of the basic concepts and basic propositions that are assumed or into which the arithmetic concepts and the arithmetic propositions respectively are translatable;

3) logicality of the truth of the basic propositions, which are not only truths but logical truths.

It is about the second aspect of logicality that a discussion may arise and the question will be: are Dedekind's fundamental concepts of his reconstruction of arithmetic, viz. the concepts 'System' and 'Abbildung', really concepts of logic? I leave the answer for the section 5.2. of the fifth and last part of my paper. Let me consider now 1).

This first aspect concerns logic as a theory of inference. It is prominent in Dedekind's striving for logical rigour ${ }^{124}$ but not thematized for itself, as it is in Frege's $B g$ and $G g$. The demands a) and c) of 1) are globally shared by Dedekind and Frege and attributed by both to "pure thought"; in fact, they are satisfied by any deductive system, or to use an expression which is appropriate for Dedekind and can be fully applied to $G g^{125}$, to any (arithmetical) axiomatic system. Logic is involved as much as in any "Euclidean" enterprise. Therefore its seems to me unnecessary to qualify Dedekind's standpoint as "logical structuralism", as did Reck (2003): any "structuralism" aims at showing the logical relations between propositions through a deductive presentation, just as any logicism deals with (formal) axiomatic systems. There is indeed a common concern: the deductive concern. But, when Frege focuses on mathematical axiomatic systems, he brings to the fore the logical elements involved in them: axioms are truths and theorems are truths inferred from axioms in accordance with the logical laws of inference. And, according to Frege, i) truths are absolute so that there is one unique axiomatic system for geometry, namely Euclid's system, and one unique system for arithmetic, namely the system of $G g$; ii) "we cannot regard as definition the system of sentences in each of which there occur several of the expressions that need defining" ${ }^{\prime 26}$. That means that a definition fixes the sense unambiguously: to a sign should be assigned, via a "constructive definition", one unique sense; a sign must not only indicate, but designate a

${ }^{124}$ Dedekind expresses his permanent concern and advice: "not renounce to use logic" in secondary school courses, e.g. in his Letter to Weber November 8, 1878, Dedekind 1930-32 III, 485.

125 "Each axiom, each assumption, each hypothesis, or whatever one wants to call it, upon which a proof is based, is brought to light; and so a basis is gained for judging the epistemological nature of the law that is proved." ( $G g$ I, Preface). Later Frege discusses the nature of axioms: Beaney 1997, 310-311.

${ }^{126}$ Frege 1979, 212. I leave out of consideration the fact that, as pointed out by Dummett, in HP the numbers introduced on the left occur within the range of the variables bounded on the right in the explicit definition of one-one correspondence. 
determined object. i) and ii) say how much Frege diverges from the mathematical understanding of axiomatics.

The demand b) is realized by Frege alone; it makes much more prominent the genuine logical aspect of deduction and brings to the light the constitution of a formal logical system, such as that of $B g$ and of $G g$.

\subsubsection{Reference to Euclid}

It is remarkable that both Dedekind and Frege refer to Euclid's system, pointing out what is lacking in it. But what is lacking according to Frege is not what is lacking according to Dedekind. For his part, Dedekind proves that any Euclidean construction is feasible using only the algebraic real numbers, and, then, that a continuity axiom is not only explicitly lacking but even not necessary in Euclid's geometrical constructions ${ }^{127}$. Moreover, Dedekind proves that Euclid's theory of proportions assumes implicitly only the Archimedean axiom, which is not sufficient to guarantee the continuity of the domain of "incommensurable magnitudes"128. Thus, Dedekind makes explicit what is logically deducible from Euclid's assumptions and what mathematical supplement is needed for reasoning correctly on continuous magnitudes or on real numbers, real functions of real variables, etc. Most people know this major contribution only through Hilbert's two continuity axioms in Die Grundlagen der Geometrie ${ }^{129}$. On the other hand, Frege shows what, according to him, goes beyond Euclid's ideal, and in the same way beyond Dedekind's achievement, namely the specification in advance of all methods of inference. That is to say that an axiomatic system, that makes explicit the deductive structure of a mathematical theory, is not yet a formally constructed logical system of that theory. Or, put differently, the logical aspect involved in an axiomatic system is not sufficient to fulfil the logicist demands.

This differentiation between 'axiomatic' and 'logicist' is the dividing line between Dedekind and Frege until the publication of $G g$, and continues after to impact Frege's conception of proofs and definitions. Whereas Dedekind is attentive to defining everything which can be defined and to proving any proposition which is provable ${ }^{130}$, in order to obtain the most simple concepts and the very primitive propositions, and hence to make clear the logical connections between mathematical propositions, he does not develop a systematic detailed reflection on logical inference in itself nor on what is or how must be an adequate definition

${ }^{127} Z$, Preface to the first edition; Dugac 1976, Appendice XXXI, and the letters to Lipschitz, Dedekind, III, 468ff.

${ }^{128}$ Letters to Lipschitz.

${ }^{129}$ Hilbert's 1899, §8, V.I: Archimedes' axiom and V.II: the linear completeness axiom.

130 "In science nothing capable of proof ought to be accepted without proof", $Z$, first sentence. 
or a correct proof. $S$ and $Z$ show practically that a definition is adequate when, starting from that definition, chains of logically correct inferences lead 1) to the definitions of usual arithmetical operations on the real numbers ${ }^{131}$ and on the natural numbers respectively, and 2) to the proof of propositions involving these operations, such as the proof of the upper bound theorem for the real numbers, the proof of the continuity of the rational operations extended to the real numbers, or the proof of mathematical induction on natural numbers. Like Frege, Dedekind did care about a "really scientific foundation for arithmetic"132 and logical rigour in his presentation [Darstellung] of the natural numbers. He insists on the long sequence of simple inferences constituting "the chains of reasoning on which the laws of numbers depend", assuming that the recognition of a mathematical truth "is never given by inner consciousness", but rather by a "step-by-step understanding"133. Our sequential understanding cannot but establish arithmetic laws progressively, by a long chain of inferences.

By contrast Frege has many comments on inferring and defining ${ }^{134}$. These comments are part of Frege's research on logic. The renewal of logic that Frege wants to achieve implies considering logic not only as giving a firm ground for arithmetic but also and mainly as a field on its own. Frege wrote a series of papers on the essence of logic in which he deals with the laws of truth and the laws of valid inference, with the definition of objects and the distinction between object and concept ${ }^{135}$ and between sense and Bedeutung, with the sharp distinction between psychology and logic (i.e. in his terms, between thinking and thought) and the affinity between logic and ethic. As Dummett points out, in large parts of these papers one cannot find any reference to mathematics nor any mention of a mathematical example ${ }^{136}$. For Frege logic applies everywhere, not only in the foundations of mathematics; it is coextensive with language, and the logical work is first a "struggle against language"137. This is a decisive

${ }^{131}$ Dedekind insists upon the fact that we must define in its entirety (up to an isomorphism) the domain of the real numbers in order to have the possibility to define in a general way the operations on it: otherwise how could we know that, e.g. the result $c$ of the addition or of the multiplication of some two individual real numbers $a$ and $b$ is again a real number. Letter to Lipschitz, June 10, 1876, Dedekind 1930-32 III, 462-474.

${ }_{132}^{132} S$, Preface.

${ }^{133} Z$, Preface to the first edition.

${ }^{134}$ Definition is treated in Gg I, $\S \S 26 \mathrm{ff}$; II, section III, $\S \S 55-65$; "Logic in mathematics", Frege 1979, 203-250, partially reproduced in Beaney 1997, 308-318.

135 "The distinction between concept and object must be kept in mind" is the third fundamental principle in $G l$.

${ }^{136}$ Frege 1979, 1-8, 137-151 (partial reprint in Beaney 1997, 201-211).

${ }^{137}$ Beaney 1997, 369. 
component of Frege's perspective on logic, a component which has triggered the linguistic turn, and which is totally absent from Dedekind's views.

\subsection{More on inference: truths and logical truths}

In $G g$ I (1893), Frege criticizes Dedekind's chains of inferences in $Z$, “the most thorough work on the foundations of arithmetic that has lately come to [his] attention. In much less space [than in $G g$ ] it pursues the laws of arithmetic much further than is done here ${ }^{138}$. This brevity is admittedly attained only because a great deal is really not proved at all"; in particular "nowhere is there to be found an inventory of the logical or other laws taken as basic" $" 139$. In fact, in $Z \$ 71$, Dedekind does list the four basic laws that, reformulated in a formal language by Peano, are known as Dedekind-Peano axioms for the natural numbers; just they are clearly not logical, i.e. universally valid, laws and they are not rules but premises of inference within a specific mathematical domain. Thus $\mathrm{Z}$ does not satisfy the aspect 3) of logicality. And as Boolos remarks: "It is evident that one who claims to have enumerated all the ideas and steps involved in mathematical reasoning need not imply that that reasoning is logical reasoning... justly, it might well be said that the Zermelo-Fraenkel set theory provides such an enumeration: to say so is, obviously, not to be committed to the view that its axioms are logical truths" ${ }^{\prime 140}$. As we know, Hilbert has been very much impressed and influenced by the deductive style of $Z$, Peano took on Dedekind's axioms for arithmetic, and Zermelo's axioms are a completed and amended version of Dedekind's axioms. Thus, Dedekind furnished the explicit basis for the multi-sided development of the axiomatic approach, which has become a fundamental constituent of mathematical reasoning. It became so clear that 'axiomatic' does not coincide with 'logical' that Frege himself admits in 1914 the possibility of general laws that are specific to mathematics, that also are not laws of logic. He even recognizes that "one can reduce a mode of inference that is peculiar to mathematics to a general law, if not a law of logic, then one of mathematics. And from this law one can then

\footnotetext{
${ }^{138}$ Frege means Dedekind's definition of addition, multiplication, and so on.

${ }^{139} \mathrm{Gg}$ I, Preface (my italics). In Frege's view "Of course the pronouncement has been already often made that arithmetic is merely a more highly developed logic; yet that remains disputable so long as transitions occur in the proofs that are not made according to acknowledged laws of logic, but seem rather to be based upon something known by intuition. Only when the transitions are decomposed into simple logical steps can one be convinced that nothing else than logic is the ground."

${ }^{140}$ Boolos 1998, 270 (my italics).
} 
draw consequences in accordance with general logical laws"141. Frege's remark applies very well to Dedekind, who indeed does not investigate logical issues in and for themselves, but aims at showing how to "establish with rigorous logic the science of numbers", namely to lay down a deductive presentation of arithmetic that bans intuition, geometric notions, and any non-arithmetical notion.

\section{On definition}

Let's turn now to definitions.

\subsection{Dedekind's definition by axioms}

Dedekind claims that he creates new concepts and, in fact, he does that by stating explicitly new primitive laws [Gesetze] or conditions [Bedingungen] for characterizing concepts intrinsically [wesentlich]. These laws are used as a definition [Erklärung] from which theorems can be deduced $(Z, 71,73$ for the sequence of natural numbers; $S, \S 5$, IV for the continuity of the domain of real numbers). Here is a point that Ferreirós brought to light: Dedekind does not use the term 'axiom' except for his continuity principle and Cantor's axiom of continuity ( $S$ Preface and $\S 3$ ); continuity is indeed not a necessary property of space whereas conditions $\alpha, \beta, \gamma, \delta$ of $Z 71$ are essential properties of natural numbers; they are, as the letter to Keferstein makes totally clear, necessary and sufficient conditions (NSC). A System $S$ is simply infinite iff there exists a distinguished element $e \in S$ and a bijective Abbildung $\varphi: S \mapsto S-\{e\}$ such that induction holds, in Dedekind's terms:

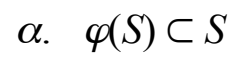

$\beta . S=\{e\}_{0},\{e\}_{0}$ is the chain of $\{e\}$, i.e. the least set containing $\{\mathrm{e}\}$ and closed under $\varphi$

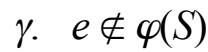

$\delta . \quad \varphi: S \mapsto S$ is injective.

Even though it may originate in Kant's view according to which there are no axioms in arithmetic, the lack of the term 'axiom' does not make $\mathrm{Z}$ a pre-axiomatic presentation. For, in Dedekind's time and before, 'essential property', 'law', and 'condition' were used as we use now 'axiom', they played the same role, and the axiomatic method was practiced long before its codification by Hilbert. The conjunction of $\alpha, \beta, \gamma, \delta$ characterizes the structure of the natural numbers as a simply infinite System: any System $S$ of uninterpreted things ("shadowslike forms") that satisfies $\alpha, \beta, \gamma, \delta$ behaves as the System $N$ of natural numbers; there is a

141 "Logic in mathematics", Beaney 1997, 309 (my italics). But this is only one first step; going further leads to construing the one logical system lying at the bottom of mathematics. 
distinguished element $e \in S$, and a bijective Abbildung $\varphi: S \mapsto S-\{e\}$ : so $\alpha, \gamma, \delta$ are satisfied $^{142}$, such that induction holds, i.e. $\beta$ is satisfied. Any such $S$ is isomorphic to $N$ (categoricity theorem, $Z$ 132), which does not mean that we can take any $S$ as the natural numbers ${ }^{143}$. If the word 'axiom' is lacking in $Z$, the thing itself is really there and makes the substance of the definition of the kind of structure instantiated by the natural numbers, which is a progression with Russell's term, an $\omega$-sequence in our terminology. Tait's provocative opinion according to which Dedekind is not "structuralist" means the following: the term 'structuralist' holds in the case where when we are asserting an arithmetic proposition $A$ we assert that $A$ holds in every simple infinite System, whereas, according to Tait, Dedekind asserts $A$ of the natural numbers themselves. Tait is fighting in particular Dummett's interpretation of Dedekind's numbers as 'structural' objects, i.e. objects "that have no properties save those that derive from position in the abstract simple infinite system (sequence of order type $\omega$ )". Indeed Dedekind specifies a structure on ordinal numbers in terms of which they can be characterized categorically by the conditions $\alpha, \beta \gamma, \delta$, and have all the properties derivable from the latter. According to Tait, defining a structure out of the numbers is a specifically logical operation. Hence Tait's view of Dedekind being a logicist. Tait judges that "Dedekind's treatment is certainly superior [to Frege's one] in at least one respect: namely, by proving the categoricity of the second-order theory of a simple infinite system he fixes the sense of arithmetic propositions independently of whether we can in some sense prove the existence of such a system; whereas not having isolated the axioms of a simple infinite system and proved categoricity, Frege's treatment of arithmetic propositions fails absolutely with the failure of his identification of them with equipollence classes of some system of objects" (1993, 31617).

\subsection{Frege's ontological conception of definitions of objects}

Frege asks: "What is definition and what can been obtained by it?" two different answers. The first one, in $G l$, is akin to Plato's ${ }^{145}$ search about what and how is that that is designated by some individual term, such as the name 'Socrates', or by some

${ }^{142}$ As noted by Dedekind this simple statement involves infinity of $S$.

${ }^{143}$ We should not forget that Dedekind's construct is based upon "a prior analysis of the sequence of natural numbers just as it presents itself, so to speak, for our consideration." (Letter to Keferstein, February 27, 1890). Worthwile discussion in Parsons 1990, 306-311.

${ }^{144} \mathrm{Gg}$ I, Preface "Es kommt hier darauf an, sich klar zu machen, was Definieren ist und was dadurch erreicht werden kann".

145 Frege recalls the Socratic aphorism: "The first prerequisite for learning ...[is] the knowledge that we do not know". ( $G l$, Introduction, Austin's edition, iii; Beaney 1997, 86; "Logic in mathematics", Frege 1979, 221). 
general term, such as 'beauty' or 'science'. It is a search after the essence, after "das Wesen der Sache". Obviously 'Wesen' and 'wesentlich' do not have the same meaning for Frege as for Dedekind. Indeed Frege's very first question in $G l$ is "what is the number one, or what does the symbol 1 mean [bedeutet]?" It is oriented to the definition ${ }^{146}$ of the number one, namely it is a question about a definite particular object, whose properties are to be specified, and simultaneously about the meaning of the symbol (singular term) by which this object is designated. Being, meaning and naming are all linked in Frege's study. Now, to say what is a particular number, such as 1 or 2 , prepares us to say what is number in general, i.e. what is the concept of number (a plural term under which fall all - possibly none or only one - the individual numbers of some specific kind, e.g. even numbers). In a Platonistic way, Frege examines first, in about $60 \S \S$, answers given by his predecessors or contemporaries and rules them out showing the logical difficulties raised by each one. Frege shows how we ought not to start from five apples, three fingers or the moon to get respectively the number five, the number three and the number one, for numbers are neither physical things nor attributes of things. There is no direct route from physical things to arithmetical objects. We should rather start with the linguistic expressions 'five apples', 'three fingers' or 'the moon', each expression taken in the context of a statement, a judgement, from which we will realize that numbers are ascribed only to concepts: "a statement of number contains an assertion about a concept" ${ }^{\prime 47}$. Frege shows how we pass from statements including a definite number, possibly zero, to this very same definite number as arithmetical object, i.e. how we pass from some plurality to a concept and then to the specified number belonging to this concept, namely the extension of this concept. More exactly a number belonging to a first-level concept $F$ is the extension of the second-level concept under which fall all and only those first-level concepts equinumerous with $F^{148}$. Thus numerical concepts are concepts of second level, then logical objects. The complete and final answer to the question "How many?" cannot be given before we "fix the sense of a numerical equation" (§ 62): the question about the definition of an object involves the search for a criterion of its identity. "If we are to use the sign $a$ to designate an object, we must have a criterion for deciding in all cases whether $b$ is the same as

146 "Is that a science which proves sentences without knowing what it proves?" (my italics); "Definitions must be given once and for all", "Logic in mathematics", Frege 1979, 216, 243. ${ }^{147} \mathrm{Gl} \S 46$.

${ }^{148}$ A difficulty arises if we ask "How do we know that for every concept there is such a thing as a number belonging to that concept?". Another question is: "how do we distinguish between the extension of a concept $C$ and the objects falling under $C$ ?" Numbers are both objects and extensions of concepts. 
a". Thus the question is threefold: 1) what is the specific object denoted by a numerical sign $a$, 2) how are numbers given to us?, and 3) which criterion permits us to recognize that the sign $a$ denotes the same object as the sign $b$ in $a=b ?^{149}$. Frege aims at constructing "the content of a judgment which can be taken as an equation on each side of which is a number" and at achieving this construction of the identity of cardinal numbers on the basis of a general concept of equality that does not hold only for numbers ${ }^{150}$ : from Hume's principle of numerical identity Frege makes a logical relation. Hence the contextual definition $\forall F \forall G(\# F$ $=\# G \leftrightarrow F \approx G$ ) called HP, and the explicit definition of the cardinal number as the class of equinumerous concepts:

$$
\# F=\text { the extension of the concept 'equal to the concept } F \text { ', i.e. }
$$

$$
\# F=[G: G \approx \mathrm{F}] \text {. }
$$

Cardinal numbers are what concepts share when they are one-to-one correspondent.

The question about the essence of numbers is also, as it was in the philosophical tradition, a question about quiddity and identity. But to answer it Frege uses a mathematical method: stating an equation. This opens the way to the "new logic" and to logical philosophy, which would replace the traditional metaphysics. Indeed, HP carries philosophical claims about the nature of number and it also provides a basis for an axiomatic system of arithmetic ${ }^{151}$. However, a logical difficulty arises from the treatment of numbers as objects that both fall under concepts and are associated with concepts as their numbers ${ }^{152}$, and an epistemic difficulty is involved in the problem of correct recognition.

Dedekind's concept of number is radically different: as we saw, Dedekind does not focus on the individual cardinal numbers nor even on the concept of cardinal number ${ }^{153}$; therefore, 1) he does not aim at deducing the numerical equality, i.e. the identity of cardinal numbers, from the one-to-one relation, 2) he does not consider the relations between proper names and individual numbers nor between general names and concepts. What concerns him is not the recognition of the identity of a singular number like, for example, 1, which may be attributed

\footnotetext{
${ }^{149}$ Frege summarizes his method as follows: "The first and most important task is to set out clearly what the objects to be investigated are. Only if we do this shall we be able to recognize the same as the same: in logic too such acts of recognition probably constitute the fundamental discoveries.", "Logic", Beaney 1997, 243.

${ }^{150} \mathrm{Gl} \S 63$, Beaney 1997, 110.

${ }^{151}$ Demopoulos 2000, 217.

152 Boolos 1998, chap.19. Parsons 1965 also displays some difficulties of the thesis that numbers are objects.

${ }^{153}$ It is a sufficient reason for why "Dedekind would not have been happy with the suggestion that the existence of infinite systems be derived from Hume's principle" (Boolos 1998, 216).
} 
to the concept under which fall so many different things (the moon, the sun, the theorem of Pythagoras, etc.), but rather a generalization of the function successor which holds not only for natural numbers but also possibly for elements which are not numbers. According to Dedekind, the linear total ordering that structures any progression and from which one can derive a general form of mathematical induction $(Z, 59)$ and the recursive definition $(Z, 126)$ of the operations of addition, multiplication, difference, power, etc. as ordinal operations is simpler than, and so prior to the cardinality aspect, which he takes to be more intricate. As to the concept of equality, Dedekind takes on Leibniz's definition of substitutability whereas Frege takes on the same definition along with the metaphysical aspect of the identity of indiscernibles.

\subsection{Frege's epistemology}

In Frege's view, the search for the definition of the concept of number is tied with an ontological assumption: numbers, thoughts, truths are timeless self-subsistent objects ${ }^{154}$, with an epistemological task, for "if at all there are logical objects - and the objects of arithmetic are logical objects - then there must be a means for grasping them, recognizing them"155. Frege's final sentence of $G g$ II is: "the prime problem of arithmetic may be taken to be the problem: How do we apprehend logical objects, in particular numbers? What justifies us in recognizing numbers as objects?". The epistemological task is double: it is about access to what is and about the justification of the judgement of recognition of what is. The answer is twofold: 1) Access is through meaning in a linguistic context. "Only in the context of a proposition do words mean something. It will therefore depend on defining the sense of a proposition in which a number-word occurs"156. Indeed, Frege thinks that we get the

\footnotetext{
154 The following passage could be interpreted as conflicting with Frege's ontological assumptions: "The self-subsistence which I am claiming for number is not to be taken to mean that a number word designates something when not in the context of a sentence, but I only intend by this to exclude the use of a number word as a predicate or attribute, which rather changes its meaning [Bedeutung]" $(G l \S 60)$. But for Dummett, the context principle is "a thesis about reference, not just about sense", it is used "to justify regarding abstract terms as standing for genuine, objective objects"; and what conflicts with it is the doctrine that truth-values are objects. Dummett 1991, $81 \mathrm{ff}$.

${ }^{155} \mathrm{Gg}$ II, $\$ 147$.

${ }^{156}$ In retrospect Frege writes: "Formerly I distinguished two components in that whose external form is an assertive sentence [Behauptungssatz]: (1) the acknowledgment of truth [this is the definition of a judgement, given in $G g$ \$5], (2) the content that is acknowledged to be true. The content I called a 'judgeable content' [beurtheilbarer Inhalt]. This last has now split for me into what I call 'thought' and 'truth-value', as a consequence of distinguishing between sense and Bedeutung of a sign. In this case the sense of a sentence is a thought, and
} 
arithmetical objects not through some kind of Kantian synthesis but through the logical analysis of arithmetical statements. What matters is always a sentence about some specified cardinal number applied to some multitude of objects, whether these objects be concrete or not, real or not. Thus a logical analysis of the language is introduced ${ }^{157}$ along with the context principle ("the meaning of a word must be asked for in the context of a proposition, not in isolation") and the radical separation between concept and object, in order to answer the ontological and epistemological question: "What is the number itself? [...] We may try to know something about the number itself from the way of using the numerals and numberwords. We use the number-words as names of objects, as proper names"158. In Frege's view the linguistic turn is closely tied with an ontological commitment. Then 2) we need a criterion for numerical identity, a criterion that decides with absolute certainty whether the object designated by a number-word $a$ is the same as the object designated by the number-word $b$. The criterion cannot be but logical since the numerals refer to logical objects that we know by analytical judgments. Contrary to Kant, Frege holds that arithmetical judgements are analytical $^{159}$ a priori and, at the same time, that logic is fruitful as a tool for clarifying what is embedded in our mathematical discourse ${ }^{160}$. Logic alone affords the needed justification for the recognition of what is.

its Bedeutung a truth-value. Over and above this is the acknowledgment that the truth-value is the True." ( $G \mathrm{~g}$ I, Preface).

157 "Work in logic just is, to a large extent, a struggle with the logical defects of language", "My basic logical insights", Beaney 1997, 323.

158 "The number", Frege 1979, 313. See also the "Notes for Ludwig Darmstaedter", Beaney, 1997, 366: "In arithmetic a number word makes its appearance in the singular as a proper name of an object of this science; it is not accompanied by the indefinite article, but is saturated".

${ }^{159}$ Needless to say that 'analytical' in Kant's conception conforms to Aristotle's analysis of a proposition into subject and predicate (the predicate is contained in the subject). With the analysis into argument and function, Frege introduces a new sense of the term analytical ( $G l$ $\S 3,16,17)$. First, analytical, synthetical, a priori and a posteriori "concern not the content of the judgement, but the justification for making the judgement". Second, for Frege analysis is a process similar to chemists' decomposition; thus a proposition resulting from an analysis (an analytical proposition) is a posteriori. But, in mathematics, justification is "finding a proof and following it back to the primitive truths". Now, "if, on the way only general logical laws and definitions are encountered, then the truth is analytic", and "if, on the other hand, it is possible to provide a proof from completely general laws, which themselves neither need nor admit a proof, then the truth is a priori." (Beaney 1997, 92-93).

${ }^{160} \mathrm{Gl}$ §17: Frege expresses the innovative view that logic can provide us with substantive knowledge; if one can, writes Frege, show the inner link of arithmetic with logic, then "the prodigious development of arithmetical studies, with their multitudinous applications, will suffice to put an end to the widespread contempt of analytic judgements and to the legend of the sterility of pure logic". §91: "propositions which extend our knowledge can contain 


\subsection{Dedekind's Treppen-Verstand and stückeweise Definitions}

As seen above, Dedekind's aim is at characterizing structurally the essence of numerical continuity and of the natural numbers. Epistemologically Dedekind keeps to the critical line of Kant. He focuses, indeed, on the power of reason and the limits of the human understanding [Verstand] rather than on Being, Truth and the justification of our recognition of them. He does not tackle proper ontological questions, because he thinks they are out of the scope of science ${ }^{161}$. Dedekind takes his starting point neither in the physical world (fingers, apples, moon, sun, strokes on a sheet of paper, etc.) nor in linguistic phrases or statements containing an indication of number. He considers straight away a scientific domain, namely elementary arithmetic, and asks what we are doing when we carry out elementary operations. And the answer comes down to excluding intuition, seeking for "inner" (structural) properties, and to promoting the step-by-step understanding [Treppen-Verstand], which is building gradually "chains of inferences" from primitive assumptions to deduced properties. Dedekind may well be considered as a great pioneer of the epistemic turn realized by structuralism: primitive assumptions are not fixed once and for all (unlike Kant, Plato and Frege); they are fixed within a given system and they vary with the system. Definitions emerge first for a restricted domain, then they are gradually generalized, for example by embedding the initial domain into more comprehensive domains under preservation of the initial operations (but not necessarily of all properties of the initial operations). They are "stückweise Definitions", which Frege rejects. Moreover, the historical aspect of knowledge is taken into account, simply because mathematical invention cannot be separated from knowledge of the previous mathematical concepts and methods ${ }^{162}$. And it is not a matter of the psychological or

analytic judgements". Frege's followers will dispute on the mathematical fruitfulness of logic: Poincaré and Wittgenstein will be against, Tarski, Abraham Robinson, Kreisel, Feferman, among others, will concretely show how logical analysis may be used as a tool for proving or discovering mathematical results.

161 "The chief task of any science is striving to ground the truth,... towards which one can but go farther [without being capable with our step-by-step understanding to attain it]. But science itself, which represents the course of human knowledge, is open to an infinite variety of presentations [Darstellungen]...it may be framed into different systems, because as human work it is submitted to arbitrariness and affected by all the imperfections of the human intellectual powers." ("On the introduction of new functions in mathematics, 1854, Dedekind 1930-32 III, 428-29, my translation, Dedekind's italics). By contrast, Frege thinks that the logical presentation of arithmetic is fundamentally unique.

${ }^{162}$ I think Dedekind would have agreed with Frege's following remark: "What is called the history of concepts is really a history of our knowledge of concepts or of the meanings of words [Bedeutungen der Wörter]. Often it is only through enormous intellectual work that knowledge of a concept in its purity is achieved, by peeling off the alien clothing that 
sociological aspects of an invention ${ }^{163}$, it is a matter of the epistemic conditions of its emergence: its content has "inner" links with previously established results so that the "image" of the whole structure is modified by it. "Progress in the development of any science reacts always again on the system thanks to which one tries to conceive of its organism, giving a new image, and that is not only a historical fact, but is also based upon an internal necessity" "164. I have shown elsewhere that Dedekind, through his influence on Jean Cavaillès, is the first contributor to our modern "conceptual history", whereas Frege originated the “conceptual analysis" practised by Gödel, Tarski, A. Robinson, Feferman and others. Frege recognizes well that "the history of discoveries is useful in many cases as preparation for further research", but this should not take the place of establishing a concept "in its purity"165. Dedekind does not see a clash between the historical process and the logical rigour in substantial advances. Dedekind's "creation of concepts" points at the working mathematician and the newly introduced practice: defining new concepts encompassing many and various results, in accordance with logical laws, for a better systematization of knowledge. The Letters to Lipschitz show clearly that Dedekind aims at a renewal of Euclid's enterprise.

\subsection{Frege's criticism of Dedekind's stückweise and creative definitions}

Frege recognizes that Dedekind's definitions are not "formal", since, in contrast with those of Thomae, Heine, Stolz or Hankel ${ }^{166}$, they do not apply to mere signs but to what express the signs. Dedekind's arithmetic is "inhaltlich" "167 and escapes "the mathematical sickness of our time, i.e. confusing sign with what is signified" "168. But Dedekind's definitions are "stückweise" and "creative". Frege fights against "das stückweise defininieren" because a

conceals it from the mind's eye." ( $G l$, Introduction, Beaney 1997, 88). But Dedekind does not consider that the history of knowledge is psychology of knowledge; knowing historically mathematical notions may lead to "peeling off their clothing" and to throwing light on ignored aspects of them.

${ }^{163}$ It is noteworthy that neither in $G l$ nor in $G g$ Frege criticizes Dedekind's way on grounds of psychologism. Dummett's psychologistic reading of Dedekind is very questionable.

164 "Die weitere Entwicklung einer jeden Wissenschat immer wieder auf das System, durch welches man ihren Organismus zu erfassen sucht, neubildend zurück wirkt, ist nicht allein eine historische Tatsache, sondern beruht auch auf einer innern Notwendigkeit.", Dedekind 1930-32 III, 430. Frege is at odds with this dynamic view: "We must always distinguish between history and system. In history we have development; a system is static...what is once standing must remain, or else the whole system must be dismantled in order that a new one may be constructed." ("Logic in mathematics", 241-242).

${ }_{165} \mathrm{Gl}$, Introduction, Austin's edition, viii; Beaney 1997, 89.

166 On the relations between Frege and Thomae and Frege and Hankel see Dathe's and Peckhaus' papers in Gabriel Gottfried \& Kienzler Wolfgang 1997.

${ }^{167} \mathrm{Gg}$ II $\S 138$.

168 "Logical defects in mathematics", Frege 1979, 158. 
definition must fit once and for all "the definiteness and fixity of the concepts and objects of mathematics"169. And Frege fights against "creation" for two mixed reasons. The first one is grounded in his questionable philosophical division of the world into two exclusive parts, the purely logical part and the rest, that can be physical or psychological. What is purely logical never changes; and it can only be discovered, not invented. Once proved, mathematical propositions are true forever, but they have been or can be proved because they are true, not the other way around. They are true even if we fully ignore them or, actually, don't recognize them as true; but we should nevertheless recognize them as true and, in order to succeed in this task, logic is the single appropriate means, because it alone allows the existence and the justification of a truth to be stated at once. The second unquestionable ${ }^{170}$ argument is logical: he points out that a mathematical definition does not create anything whose existence has not been proved beforehand. But one may wonder whether Frege himself should not have, in $G l$, proved the existence of the finite cardinal numbers before defining them. In fact, he just assumes these numbers to be logical, self-subsistent objects; hence he credits them with a timeless existence in a "third realm" whose elements are permanently either true or false. Is this to say that, if the logical reduction succeeds, then the question of existence is also reduced just to make precise in what sense logical objects exist? Or rather, even with the logical construction of arithmetical objects, the question of existence persists and is only pushed to the level of extensions of concepts, as Russell will show? Until 1903 Frege faces neither the first nor the second question, because of two strong ontological assumptions: 1) he has no doubt that logical objects exist independently from space, time and cognitive acts and 2) he believes that the numbers "are immediately given" to reason. We do not have to prove the existence of something whose existence is immediately given to us; this is why the definition of cardinal numbers in $G l$ presupposes from the outset the existence of these numbers and provides rather a logical criterion for their equality or identity. In $G g$ II $\S 143$, Frege relates the creative definitions to Otto Stolz, and he states that a mathematician should, before performing a creative act, prove that the properties that he will attribute to the object he wants to create do not mutually contradict, but he can only prove that by proving that there exists an object which has all the properties in question. And if he can prove that such an object exists, then he does not need to create it. This criticism points out a difficulty for purely formal theories, i.e. in Frege's sense, theories for which no model is known in advance. Frege is

\footnotetext{
${ }^{169}$ Gl, Introduction, Beaney 1997, 89.

170 Unquestionable in the general case, but for first-order theories consistency entails existence by Gödel's completeness theorem (1930).
} 
right: Dedekind is not formalist in this sense; he is indeed speaking not of creating objects but of creating concepts that bring to the light the inner structure of a family of Systems of objects. Indeed, Dedekind writes to Keferstein that the fundamental properties $(\alpha, \beta, \gamma, \delta)$ of natural numbers must be mutually compatible, independent from each other, and sufficient for deriving all arithmetic theorems. But he does not seek to demonstrably show the compatibility and the independence of the properties in question nor the coincidence between arithmetic truth and theorem derivable from $(\alpha, \beta, \gamma, \delta)$. The reason is given by Dedekind himself: he found out those properties "after protracted labour, based upon a prior analysis of the sequence of natural numbers just as it presents itself, in experience, so to speak, for our consideration" ${ }^{\prime 171}$. In modern terms, Dedekind construed the theory of a model, whose consistency is therefore beyond doubt. For a working mathematician that suffices to avoid the problem posed by Parsons (1990) of the possible vacuity of arithmetical statements. But that was not as clear as today, and, in any case, the philosophical question of the mode of reality of mathematical entities still remains. Anyway, Dedekind already feels in the late 1880s the need to prove the non-contradiction of his concept of infinite Systems, on the basis of which the whole domain of numbers lays, and he attempts to build a proof in $Z 66 .{ }^{172}$ Such a proof might have been felt necessary since actual infinite systems constitute a mathematical object different in nature from the given sequence of natural numbers. Dedekind addresses, regarding actual infinities, the existential/ontological question that he generally leaves untouched, but the proof failed. Frege's alternative solution, namely "to transform the generality of an equation into an equation" between logical objects ${ }^{173}$ comes up against the

${ }^{171}$ Letter to Keferstein February 1890, 27, van Heijenoort 1967, 99.

${ }_{172}$ Something like "theorem 66" is lacking from the first draft (Dugac 1976, Appendix LVI).

173 "Wenn es überhaupt logische Gegenstände giebt - und die Gegenstände der Arithmetik sind solche - so muß es auch ein Mittel geben, sie zu fassen, zu erkennen. Und dazu dient uns jenes logische Grundgesetz, das die Umwandlung der Allgemeinheit einer Gleichheit in eine Gleichheit erlaubt. Ohne ein solches Mittel wäre eine wissenschaftliche Begründung der Arithmetik unmöglich. Es dient uns zu den Zwecken, die durch das Schaffen neuer Zahlen bei anderen Mathematiker erreicht werden zollen... Jedenfalls ist unser Schaffen, wenn man es so nennen will, kein schrankenloses, willkürliches, sondern die Weise des Vergehens und ihre Zulässigkeit ist ein für alle Malle festgestellt. Und so fallen hier alle die Schwierigkeiten und Bedenken hinweg, die sonst die logische Möglichkeit des Schaffens in Frage stellen; und wir können hoffen, mit unsern Werthverläufen Alles das zu erreichen, was auf jenen anderen Wegen verfehlt worden ist" ( $G g$ II, §147). "Wir haben uns an unsere Umwandlung der Allgemeinheit einer Gleichheit in eine Werthverlaufsgleichheit erinnert, die uns das zu leiten verspricht, was die schöpferischen Definitionen anderer Mathematiker nicht vermögen" $§ 157$. 'Allgemeinheit' is expressed by the universal quantifier. 
existence of extensions of concepts ${ }^{174}$. The failure of Dedekind's proof and of Frege's basic law V led Russell and Zermelo to admit an axiom of infinity along with the arithmetical axioms, which finally comes down to accept "creative definitions" (whatever ontological status may be so ascribed to the introduced entities).

\subsection{Frege's technical conception of definitions}

The second way of Frege's conception of definitions is rather more technical than ontological. It is linked with the construal of a formal system whose primitive signs stand for logical objects and primitive laws are assumed to be purely logical. But even in this technical sense where "definition is really only concerned with signs", a definition fixes once and for all the sense of a sign, because the logical system to be construed is unique ${ }^{175}$. In "Logic in mathematics" Frege distinguishes two different cases ${ }^{176}$. First, definitions proper or "definitions tout court" are "constructive [aufbauende] definitions" in the sense that we "construct a sense out of its constituents and introduce a sign to express this sense". A definition tout court "is an arbitrary stipulation which confers a sense on a simple sign (the definiendum) which previously had none. This sense has ... to be expressed by a complex sign (the definiens) whose sense results from the way in which it is put together". Since there is one unique system of logic, definition in this sense is an arbitrary stipulation, but once made it must remain the same everywhere in the system. Moreover, we can dispense with the newly introduced, abbreviating, sign, and keep the definiens. Thus, from a logical point of view, argues Frege, definition is quite inessential. If so, the question arises immediately why Frege invested so much care to define, explicitly and contextually, the concept of cardinal number ${ }^{177}$. Now, what may be called an "analysing definition" [zerlegende Definition] is the reverse procedure; it consists of a logical analysis of the sense of a long-established sign (or concept word), which provides a complex expression that is assumed to have the same sense as the long-established sign, when the analysis is correct. But how can one recognize the correctness? Indeed, the sameness of sense is open to question. Frege answers that it can be grasped only when it is self-evident and can be "recognized by an immediate insight". "And

${ }^{174}$ It has been remarked that in $G l$ Frege makes no use of extensions once HP is derived (§73). By contrast, extensions (value-ranges) are used throughout $G g$; however Heck (1993) shows that values-ranges are eliminable except in the proof of HP.

${ }^{175}$ This is the essential reason why Frege does not have the notion of logical consequence, let us say from a set $S$ of logical formulas to a logical formula $A$; he does not have the view of considering a formula under a range of interpretations.

${ }^{176}$ Beaney 1997, 316ff.

${ }^{177}$ See, e.g., Dummett, "Frege and the paradox of analysis", in Dummett 1991, 17-52. Note in passing that Frege does not use 'explicit'. 
then what we have is an axiom" 178 . Indeed, Frege holds that the analysing definition is "really to be regarded as an axiom", and adds that an axiom is a relative notion ${ }^{179}$. We are far from the view of $G l$ according to which a definition, not an intuition, must capture the very essence of a thing ("what is the number itself"). The intervening intuition here plus the relativity of axioms are two reasons for Frege's rejecting "analysing definitions" as being not definitions proper. However, if it is right that axioms generally result from an analysis of the received sense of some mathematical concepts or objects, the new concepts yielded by the stipulation of the axioms obtained by analysis have generally not the same sense as the previous ones, but precisely a new sense. Why does Frege want that sense be preserved from a longestablished sign up to a new axiom? Because Frege just cannot accept that senses, that is to say thoughts or thought-constituents, may evolve. What is evolving according to him is only our knowledge of them, and that happens through elucidations [Erläuterungen] that make clearer a sense that existed before but was grasped only in an unclear or partial way ${ }^{180}$. Frege proposes regarding logical analysis "only as a preparatory work which does not itself make any appearance" in the system to be constructed from the ground up on the basis of a proper definition, namely a constructive definition.

This conception is partly close to Dedekind's brief genealogical description in the letter to Keferstein (February 27, 1890). Dedekind splits the mathematical work into analysis and

${ }^{178}$ That's the paradox of "logical analysis" resulting into an immediate insight and yielding an axiom instead of giving an equation each member of which is a logical object. Regarding worries caused by the expression 'zerlegende Definition' and the relation of the latter with the "analytische Wahrheiten" and the 'analytische Grundsätze' of $G l$ (e.g. §§ 3, 4), where we do not find 'analytische Definition' but 'Auflösung der Begriffe' for 'conceptual analysis', see Dummett 1991. Dummett takes 'zerlegende Definition' as meaning 'analytic definition'. I am standing on the side of Beaney's warning: 'zerlegende Definitionen' are not 'analytisch' in the Kantian sense. Beaney adds that "we might say, where a definition is 'analytic' ['analytisch'], then it must be understood as either a 'constructive definition' ['aufbauende Definition'] - which, I suppose, would correspond to the general definition of individual cardinal numbers in $G l$ and $G g$ - or an 'axiom' " (Beaney 1997, 316, footnote 10). But if 'analytic' definitions may be 'axioms', the task would remain to explain why Frege continues as late as in 1914 to reject axioms outside the system proper. After all there are not only logical concepts and objects, but also logical axioms, "basic laws" in Frege's terminology.

179 "It is really only related to a particular system that one can speak of something as an axiom" ("Logic in mathematics", Beaney 1997, 311), but the truth of a proposition that can be an axiom is not relative. Compare with Dedekind's view according to which "Drehen und Wenden der Definitionen, den aufgefundenen Gesetzen oder Wahrheiten zuliebe, in denen sie eine Rolle spielen, bildet die größte Kunst des Systematikers". Yet in mathematics this turning and shifting leaves no room for arbitrariness. (Dedekind 1930-32 III, 430).

180 "The effect of logical analysis [...] will be precisely this - to articulate the sense clearly" ("Logic in mathematics", Beaney 1997, 317); one also finds an explication in the sense of Carnap. 
synthesis, endorsing the sense given to these two terms by the Ancient. A long-standing analysis of the pre-theoretic sequence of natural numbers allowed the axioms for the synthetic presentation of $Z$ to be found. Contrary to Frege, Dedekind makes no radical difference between axiom and definition: as stated above, his four axioms (conditions $\alpha, \beta, \gamma, \delta$ ) for the natural numbers are stated as definitions 71 and 73; similarly the continuity axiom is stated as the fourth basic law for defining the real numbers $(S \S 5)$. By 'axiom' Dedekind means 'defining condition' ${ }^{181}$, while Frege wants it to be a basic logical truth. Dedekind does not encounter Frege's problem with the coincidence of the result of analysis with our pre-analytic conception; he readily admits that a reader of $Z$ "will scarcely recognize in the shadowy forms [he] brings before him his numbers which all his life have accompanied him as faithful and familiar friends" $" 182$. The shadowy forms, not the familiar numbers, are a free creation of the human mind. Practice will provide them with familiarity and some kind of substance.

\subsection{Frege's and Dedekind's philosophical assumptions}

For both, Dedekind and Frege, mathematical or rational thought is objective in the sense given above (3.2.1. to 3.2.4.). But for Dedekind mathematical thinking is a creative and evolving activity, whereas for Frege, paradoxically, 'thought' has nothing to do with 'thinking', since it does not have to be thought at all. A thought is the sense [Sinn] of a sentence $[\mathrm{Satz}]$; a sentence expresses a thought, which is permanently either true or false (tertium non datur). So the Bedeutung of a sentence is its truth-value, in a way parallel to that which assigns to a name its bearer as Bedeutung. According to Dummett" ${ }^{183}$ "to know the sense is to know the condition fort the expression to have a given reference", in the same way as knowing the sense of a name is knowing a mode of presentation of its referent. "I begin" wrote Frege - "by giving pride of place to the content of the word 'true', and then immediately go on to introduce a thought as that to which the question 'Is it true?' is in principle applicable" ${ }^{184}$. The Begriffsschrift was invented in order to make easier the control of the validity of proofs and presented logic as a theory of inference. From the 1890s onwards logic will appear as a theory of truth. Truth becomes the central affair of logic, its aim ${ }^{185}$ : the

\footnotetext{
${ }^{181}$ Hellman 2005, 537.

${ }^{182} Z$, Preface to the first edition.

183 "Frege as a realist", Dummett 1991, 87. Discussion in Parsons 1965.

184 "Notes for Ludwig Darmstaedter", Beaney 1997, 362.
}

185 Its aim or goal, not its essence, which is "the assertoric force with which a sentence is uttered" ("My basic logical insights", Beaney 1997, 324). "The word 'true' indicates the aim of logic just as does 'beautiful' that of aesthetics or 'good' that of ethics. All sciences have truth as their goal; but logic is also concerned with it in a quite different way: it has much the same relation to truth as physics has to weight or heat. To discover truths is the task of all 
laws of logic are the laws of the True and the False. What True is, is undefinable ${ }^{186}$. Yet, thoughts constitute a "third realm" of changeless entities, and "the work of science does not consist in creation, but in the discovery of true thoughts"187. "In thinking we do not produce thoughts, we grasp them" ${ }^{\text {"188 }}$. To grasp a thought is to know the condition for it to be true. We need to separate the content from the act of thinking so that we can provide the content, the thought, with a criterion of identity independent from the subject's mental life. The most Frege can concede is that thoughts have a kind of actuality "quite different from the actuality of things" and that "their action is brought about by a performance of the thinker". And yet the thinker does not create thoughts, nor can he react on them, he just "must take them as they are" ${ }^{189}$. There is absolutely no ambiguity: Frege's universalistic conception of logic and truth is backed up with a ontological realism, which, unsurprisingly, goes so far as to finally admit a logical intuition intervening in grasping logical objects, recognizing their logical identity, and making a judgement about their being true or false. It would be wrong to conceive of grasping, recognizing, judging as our acting on thoughts. It is rather the case that "it may be possible to speak of thoughts as acting on us"190. Dummett notes that Frege's realism, the "myth of the third realm"191, is certainly not "a logical precondition" of his major achievements in logic ${ }^{192}$; yet it is a philosophical assumption, which Frege maintains and even reinforces until the last years of his life: his permanent concern is to isolate the logical from any psychological process and to separate the sense (thought) from its linguistic expression. Carnap wrongly exempts Frege from holding the "absolutist conception" and the "theological

sciences; it falls to logic to discern the laws of truth... I assign to logic the task of discovering the laws of truth, not the laws of taking things to be true or of thinking.", "Thought", Beaney 1997, 325-326.

186 "Key sentences on logic", Frege 1979, 174 ; "Logic", Beaney 1997, 228 (thi is a remarkable foreinsight of Tarski's undefinability theorem).

187 “Thought", Beaney 1997, 342.

188 “Thought”, Beaney 1997, 341-342.

189 "Thought", Beaney 1997, 345; "Logic": "The metaphors that underlie the expression we use when we speak of grasping a thought, of conceiving, laying hold of, seizing, understanding, of capere, percipere, comprehendere, intelligere, put the matter in essentially the right perspective. What is grasped, taken hold of, is already there and all we do is take possession of it." (Beaney 1997, 237).

190 "Logic", Beanay 1997, 238. Compare with Gödel's more affirmative opinion about the axioms of set-theory, which " force themselves upon us as being true." (Gödel 1964, 268).

${ }^{191}$ That our current understanding of mathematical realism, which originates from Bolzano's "Sätze an sich" and Frege's "third realm", does not fit with Plato's account of the being of mathematical objects is soundly argued by Tait 1986a, 1993, and McLarty 2005, whose conclusion is: "Plato was not a mathematical Platonist". Hence my discriminant use of 'realism' and 'Platonism'.

192 “Frege as a realist”, Dummett 1991, 80. 
mathematics" that he attributes to Ramsey, probably just for providing an ancestor to his own empirical logicism.

What may be said concerning Dedekind's philosophical assumptions? Dedekind is definitely not a realist: he promotes actual infinities but does not think them to exist independently of our thinking. In accordance with Kantian optimistic rationalism, mathematical concepts are created and objective, they are abstract but they are not genuine self-subsistent objects which is the distinguishing mark of Frege's logical objects. Now, can Dedekind be taken as a non-realist logicist? In other words, how can one think of Dedekind's structuralism as being a form of logicism?

\section{5. 'System' and 'Abbildung', structuralism, logicism}

I will tackle now the outstanding question: are Dedekind's fundamental concepts of his reconstruction of arithmetic, viz. the concepts 'System' and 'Abbildung', really concepts of logic?

\subsection{Concept}

When he does not use it as a synonym for the vague term 'notion', Dedekind understands 'concept' ['Begriff'] as a domain ['System' in Dedekind's terminology] + operations on the domain, that is to say a "structure" in our modern language. Dedekind, as most of his contemporaries or later followers like Hilbert, Emmy Nœther, B.L. van der Warden, Emil Artin, etc., does not use the term "structure", that has been most popularized by the Bourbaki enterprise. And yet Dedekind is the mathematician with whom structuralism originates, without providing "a theory" of abstract structures. Already in 1854, Dedekind uses 'System' and 'systematizing' for 'structure' and 'structuring' respectively ${ }^{193}$. Indeed, 'systematizing' means isolating primitive assumptions from their logical consequences. Later, in Z, 'System' means 'domain of uninterpreted elements', and affords the basis for defining general operations whose instantiations will be the definition of finite ordinal numbers and the recursive definition of arithmetical operations: +, x, etc. A System results from a unifying point of view ${ }^{194}$, and is identified with its extension; in our current term it is a set. Moreover, Dedekind's reference to Euclid's Elements, to Galois, to Riemann, among others

193 "Die weitere Entwicklung einer jeden Wissenschat immer wieder auf das System, durch welches man ihren Organismus zu erfassen sucht, neubildend zurück wirkt, ist nicht allein eine historische Tatsache, sondern beruht auch auf einer innern Notwendigkeit.", Dedekind 1930-32 III, 428.

${ }^{194} Z \S 1.2$. 
"Systematikers"195, his strong interest in the deductive character of a theory, and his use of the analysis/synthesis method leave no doubt about his promoting structuralist mathematical practice $^{196}$. Logic is necessary for this promotion. But mathematical substance is also indispensable. Dedekind's historical concern is a precondition of the search for firm grounds, and both attitudes, grounding and transforming the mathematical substance, are tightly bound with a close eye on the practice and its history ${ }^{197}$. As learnt from looking at the history, "the greatest and most fruitful advances in mathematics and other sciences have invariably been made by the creation and introduction of new concepts" ${ }^{\text {"198 }}$. New concepts are conceived of as new modes of determination [Art der Bestimmung], or modes of presentation [Darstellung] that meet a higher standard of logical rigour and respect the hierarchy which places arithmetic at the head of the whole mathematical body. One can say that Dedekind's 'concept' is close to one aspect of Frege's 'sense', when sense is related to Bedeutung as being a way in which a Bedeutung is given, while the other side of a sense consists in its being itself a logical object offered to our possible grasping ${ }^{199}$. But on the one hand, Dedekind's concern is far from elaborating the ontological and logical status of concepts. He endorses the Kantian conception of concept as being the human power to organize and unify things, a thing being "every object of our thought" ${ }^{200}$, i.e. a thought-object. A concept has no existence independent from our mind; it was not already there ${ }^{201}$; it is created as a tool for grounding and generalizing mathematical methods and for opening new perspectives for the mathematical activity as well. On the other hand, Dedekind does not elaborate upon the distinction he makes sometimes ${ }^{202}$ between object and concept and, in particular, he naturally does not see a concept as a step in the identification of an individual object, let alone as a step in the determination of the truth-

\footnotetext{
${ }^{195}$ Dedekind 1930-32 III, 430.

${ }^{196}$ Parsons 1990, 306-311; Schlimm 2000; Sieg and Schlimm 2005; McLarty 2008a.

197 "Diese Vorlesung hat nicht etwa [...] die Einführung einer bestimmten Klasse neuer Funktionen in die Mathematik, sondern vielmehr die Art und Weise [my italics] zum Gegenstande, wie in der fortschreitenden Entwicklung [my italics] dieser Wissenschaft neue Funktionen, oder, wie man ebensowohl sagen kann, neue Operationen [Dedekind's italics] zu der Kette der bisherigen hinzugefügt werden." (ibid., 428).

${ }^{198} Z$, Preface to the first edition.

${ }^{199}$ For a criticism of Frege's twofold conception of sense see Dummett 1992, 276-281.

${ }^{200} Z$ I.1.

${ }^{201}$ This character makes Dedekind's 'concept' close to the middle ages 'universals'(contrary to Boolos' suggestion $(1998,149)$, it's not so easy to give the same ontological status to Plato's Forms and universals).

${ }^{202}$ Letter to Lipschitz July 27, 1876; Letter to Weber January 24, 1888 (Dedekind 1930-32 III).
} 
value of thoughts related to the identifiable object. As above-said Dedekind does not tackle the question of mathematical, less alone of logical, truth.

As is well known, Frege makes a very specific use of 'concept'. First understood as a function of one argument resulting from the decomposition of judgeable contents $(B g)$, and entailing the opposition to object, concept appears in $G l$ to be the bearer of numbers, and it is defined in $G g$ as a function from objects to truth-values, taken extensionally, thus presupposing the step from the level of sense to the level of Bedeutung ${ }^{203}$, then from concepts to extensions. Frege regards the passage from a concept to its extension as the only way of inferring the existence of an object on logical grounds ${ }^{204}$. While there are different kinds of (logical) objects: numbers, thoughts, truth-values, extensions of concepts, value ranges, concepts are uniformly understood as relations (of different levels ${ }^{205}$ ) which are essentially "unsatured", just as is unsatured a mathematical function $f$, and then are prior to their extensions ${ }^{206}$. Hence the radical distinction between concept and object: they are completely different sorts of entities (third fundamental principle of $G l$ ). Concept is nevertheless something objective ${ }^{207}$ : concept and object are on the same level of objectivity ${ }^{208}$, the criterion for the identity of an object and the objectivity of a concept being given by logic alone.

As is known, such a radical distinction between concept and object involves difficulties from the logical point of view ${ }^{209}$, and also from the point of view of mathematical practice. Not surprisingly, Dedekind's 'concept' is not submitted to Frege's demand of distinguishing radically and once and for all 'concept' and 'object'. More exactly, Dedekind makes a distinction between 'object' and 'concept', the first term meaning individual objects and the second term meaning a whole domain equipped with some operations and laws governing them. For instance Dedekind writes to Lipschitz (July 27, 1876) that he intended not to invent a "new object for mathematical research" or unknown irrational numbers, but to define at

203 "Judgements can be regarded as advances from a thought to a truth-value", "On Sinn and Bedeutung", Beaney 1997, 159. "The laws of logic are first and foremost laws in the realm of Bedeutungen and only relate indirectly to sense", "Comments on On Sinn and Bedeutung", Beaney 1997, 178.

204 "And even now I do not see how arithmetic can be scientifically established; how numbers can be conceived as logical objects and brought under consideration, unless we are permitted - at least conditionally - to pass from a concept to its extension." (Gg II, Appendix, 253).

${ }^{205}$ A concept under which objects fall is a concept of first level, a concept under which fall concepts of first level is a concept of second level, etc.

${ }^{206}$ From a structuralist stand domain and operations are correlated: a given domain of elements may be equipped with some operations, the operations generate a new domain.

${ }^{207} \mathrm{Gl} \S 47$.

${ }^{208}$ Letter to Husserl, 24.5.1891, Beaney 1997, 150.

${ }^{209}$ See Russell 1903, Appendix A. 
once the complete domain of irrational numbers, to define also intensionaly the concept of irrational number without considering the individual numbers that fall under the concept; that is to say to define the algebraic ordered structure of the domain by listing a small number of properties to be satisfied. From a logical point of view we are in a second-order language, and, from Frege's logical point of view, we are dealing here with objects only, as individuals (real numbers) and as extensions of concepts (the domain of real numbers). Dedekind's concept/structure may become in its turn what mathematicians treat as an object by a process that Husserl calls thematization. I don't wish to discuss here on what structures and objects are, but just to seize the irreducible difference between Dedekind's and Frege's use of the words 'concept' and 'object'. Frege's numbers are individual logical objects; Dedekind's numbers instantiate an uninterpreted (abstract) structure, which is itself "the first object of the science of numbers or arithmetic" 210 .

Frege's sophisticated notion of concept is connected with that of truth-value, which is the decisive step for a semantic theory, and which is absent from Dedekind's works (as is a syntactic theory also absent ${ }^{211}$ ). In $G l \S 74$, Frege writes "On my use of the word 'concept', ' $a$ falls under the concept $F^{\prime}$ is the general form of a judgeable content which deals with $a$ and remains judgeable whatever stands for $a$ ". According to Frege's mature theory, a concept is a function whose values are not judgeable contents, but truth-values. In Frege's schema given in a letter to Husserl ${ }^{212}$, one sees the permanent correlation between sense and Bedeutung (reference) and the analogical role of proposition, proper name and concept word: for a proposition sense is thought and Bedeutung is truth-value; for a proper name sense is correlated with object; the Bedeutung of a concept word is the concept itself $^{213}$ as distinguished from its extension (the objects - possibly none - falling under it). Objects, truthvalues, concepts are all the reference of expressions of different logical types; truth-values and concepts are abstract objects, i.e. logical objects. Dummett sees the equation of

${ }^{210} Z$ 73: "The relations or laws which are derived entirely from the conditions $\alpha, \beta, \gamma, \delta$ in 71 and therefore are always the same in all ordered simply infinite systems, whatever names may happen to be given to the individual elements (compare 134), form the first object of the science of numbers or arithmetic" (Dedekind's italics).

211 I am not saying that a semantic point of view is absent in Dedekind's work, I am saying that a semantic theory or theory of truth is absent. Likewise I am not saying that Dedekind has no syntactic views, I am saying that he has no syntactic theory or theory of inference.

212 Beaney 1997, 149-150.

${ }^{213}$ Dummett observes that "We can make no sense, for example, of the thesis that the content of a statement of number consists in predicating something of a concept unless we view the concept as being the reference of the concept-word" (Dummet 1991, 235, Dummett's italics). 
Bedeutung with semantic value as the first stone for constructing a compositional semantic theory: Frege assigns a reference to the constituent parts of a sentence so that the sentence is true or false in accordance with the truth or falsity of its components ${ }^{214}$. But in HP, i.e.

$$
\forall F \forall G(\# F=\# G \leftrightarrow F \approx G),
$$

\# is the sign of a function from concepts to objects such that any two concepts are assigned the same object iff they are equinumerous. The existence of such a function is questionable; then HP is not logically true.

\subsection{System and Abbildung, generality}

Now, not retrospectively within our current set-theoretic or another frame, but from Dedekind's own point of view are 'System' and 'Abbildung' concepts of logic?

A first answer is easy: for Dedekind these concepts result from fundamental operations of the understanding and then are more general than the numerical operations proper. This type of generality explains the applicability of these operations not only to arithmetic, but also to other mathematical branches and elsewhere. Once we have brought into light the structure of totally ordered simply infinite (countable) Systems, we can transfer this structure, for example to the domain of algebraic numbers and algebraic functions, as actually done by Dedekind and Weber. There is no doubt that Dedekind views the ascent from arithmetic proper to general "arithmetizing", i.e. to arithmetical structures, as a logical ascent - and this is probably one reason why Tait takes him as a logicist; but Dedekind understands logic as the structure of the operative mind and not as a structure that the mind should recognize as independent from itself. Frege comes close to that only once, when he appeals to "the logical disposition of man"215.

5.2.1. Dedekind's conception of the operative mind and Cantor's paradox

Indeed, a System results from "the creative power [Schöpferkraft] of the mind to create out of determinate elements a new determinate element which is their System" ${ }^{\text {216; }}$; this power is crucial for Dedekind who considers natural numbers as forming an autonomous System and who introduces actual infinities. $Z$ is grounded upon the "aggregative thought" so harshly

\footnotetext{
${ }^{214}$ Dummett distinguishes between thesis $(\mathrm{T})$ that truth-values are the referents [Bedeutungen] of sentences and thesis $(\mathrm{O})$ that truth-values are objects. He says: $(\mathrm{O})$ is objectionable, but $(\mathrm{T})$ is not.

215 "Sources of knowledge of mathematics and natural sciences", Frege 1979, 269.

${ }^{216} Z$, Preface to the third edition. Taking this time 'concept' in its common meaning, Frege writes similarly: "The power of collecting together that a concept has far surpasses the unifying power of synthetic apperception" $(G l \S 48)$.
} 
criticized by Frege. System is also named aggregate, manifold or totality, and Dedekind deals with "object[s] of our thinking" 217 , rather than with objects of thought, because he holds essential passing from things to a System of them, a procedure informally used by Dedekind a long time before its explicit setting. Frege rejects this procedure as being outside logic although according to Dedekind it consists in forming a concept, the latter being considered as an object of our thinking (a thought-object) ${ }^{218}$. Dedekind is convinced that the fundamental operation "set of" must be preserved anyway and that a logical solution will certainly be found for the logical flaw emerging from its use ${ }^{219}$, because sets are linked with the most fundamental operation, the Abbilden-ability. Dedekind did not try himself to overcome the difficulty; he was not even willing to face up to it. As is well known Cantor communicated, several times, what we call Cantor's paradox to Dedekind. First, Felix Bernstein reported that, in winter 1896/97, Cantor wrote to Dedekind about the paradox of the set of all things and asked him to take a position on this default of his construction ${ }^{220}$. In his famous letter of August 3, 1899221 , Cantor came back to his distinction between consistent and non-consistent multiplicities, and, in a letter of August 28, 1899, he asked Dedekind for a discussion in a face-to-face meeting ${ }^{222}$. But Dedekind resisted to the idea that there might be infinities that cannot be actual or cannot be brought to constitute a consistent System. He writes:

“ ...zur Diskussion Ihrer Mittheilung bin ich noch lang nicht reif... obgleich ich ihren Brief vom 3. August mehrere Male durchgelesen habe, mir über ihre Eintheilung der

${ }^{217} Z 1$ (my italics):"“Im folgenden verstehe ich unter einem Ding jeden Gegenstand unseres Denkens... ein System $S$ (oder ein Inbegriff, eine Mannigfaltigkeit, eine Gesamtheit) ist als Gegenstand unseres Denkens ebenfalls ein Ding". 'Thinking' does not have a subjective meaning as it has in Frege's mind.

${ }^{218} Z$ 2: "It very frequently happens that different things $a, b, c, \ldots$ for some reason can be considered from a common point of view, can be put together in the mind, and we say that they form a System $S$; we call the things $a, b, c, \ldots$ elements of the System $S ; \ldots$ conversely, $S$ consists of these elements".

${ }^{219} Z$, Preface to the third edition. Gödel thinks too that set-theoretical paradoxes are "a very serious problem, not for mathematics, however, but for logic and epistemology". He also already points out the analogy between the "naïve" use of the concept of set, understood as the generating of unities out of manifolds, and Kant's categories of pure understanding (Gödel 1964, 268, ftn. 40).

${ }^{220}$ Dedekind 1930-32 III, 449.

${ }^{221}$ Published together with the letter of August 28 as a single letter in Cantor 1932, 443-447. See Dugac 1976, 130, 259-260: "Eine Vielheit kann nämlich so beschaffen sein, daß die Annahme eines 'Zusammenseins' aller ihrer Elemente auf einen Widerspruch führt, so das es unmöglich ist, die Vielheit al eine Einheit, als ein 'fertiges Ding' aufzufassen. Solche Vielheiten nenne ich absolut unendliche oder inkonsistente Vielheiten. Wie man sich leicht überzeugt, ist, z.B. der 'Inbegriff alles Denkbaren' eine solche Vielheit”. Detailed comments in Parsons 1977.

${ }^{222}$ Dugac 1976, 260 (the last section of the letter has been not published by Zermelo). 
Inbegriffe in konsistente und inkonsistente [Vielheiten] hoch nicht klar geworden bin; ich weiß nicht, was Sie mit dem „Zusammensein aller Elemente einer Vielheit“ und mit dem Gegentheil davon meinen “223.

Finally, on September 4. 1899, after a convivial meeting with Cantor, Dedekind confessed that Cantor did give the "coup de grace" to his error ${ }^{224}$. Nonetheless, he did not try at all to search for the means to neutralize the paradox. In a brief new preface to the third edition of $Z$ (1911), at a time when Frege's Gg (1893, 1903), Russell's Principles of mathematics I (1903), Hilbert's first paper on the "Foundations of logic and arithmetic" (1905), Zermelo's Investigations on the foundations of set theory I (1908b), and the first volume of Whitehead' and Russels's Principia Mathematica (1910) were already published, Dedekind wrote that he did not doubt of the intrinsic value of his mathematical foundation, leaving to others the task to amend the logical flaw. Surprisingly he did not even mention Zermelo's amendment through the "Aussonderungsaxiom" and the assumption of an infinity axiom. He probably considered not his job to take on logical aspects of axiomatized set theory, while the mathematical part of the construction has been well done ${ }^{225}$. Dedekind views Systems as "logical" operations of the mind, but not so far as to tackle the logical difficulty involved in their unrestrictive use. Indeed a mathematical theory carried out in a logically inconsistent system need not to be ruined by the inconsistency.

\subsubsection{Dedekindian abstraction.}

Tait explains the procedure as follows: starting with, for example, von Neumann finite ordinals, "we may abstract from the particular nature of these ordinals to obtain the system $\mathcal{N}$ of natural numbers. In other terms, we introduce $\mathcal{N}$ together with an isomorphism between the two systems. In the same way we can introduce the continuum, for example, by Dedekind's abstraction from the system of Dedekind's cuts". ${ }^{226}$ One may say that, in Tait's analysis, 'abstraction' has just the same meaning as 'idealization' in Husserl's terminology. Indeed, Tait sets in contrast Platonistic idealization with Aristotelean abstraction from sensible things. According to him, modern mathematics is "inalterably Platonistic" in a sense faithful to

\footnotetext{
${ }^{223}$ Dugac 1976, 261.

${ }^{224}$ Landau 1917, 54.

${ }^{225}$ Parsons 1977 uses modality in order to save the idea that any multiplicity of objects can constitute a set: "The idea that any available objects can be formed into a set is, I believe, correct, provided that it is expressed abstractly enough, so that 'availability' has neither the force of existence at a particular time nor of giveness to the human mind, and formation is not thought of as an action or Husserlian Akt. What we need to do is to replace the language of time and activity by the more bloodless language of potentiality and actuality." By the way, Dedekind's operation or activity of mind follows a Kantian line.

${ }^{226}$ Tait 1986a, 369, footnote 12.
} 
Plato's writings, whereas the use of "Platonism" to refer to the view that mathematical objects "really" exist does not fit Plato's theories ${ }^{227}$.

Dedekind's question is not "What is the number itself?", but "What is done in counting"228. From analysing the actual process of counting in the model into practice we are lead to consider ordinals, i.e. counting numbers, and we can answer the question: "What are the fundamental properties of the sequence $N$, that is, those properties that are not derivable from one another but from which all others follow? And how should we divest these properties of their specifically arithmetic character so that they are subsumed under more general notions and under activities of the understanding without which no thinking is possible at all but with which a foundation is provided for the reliability and completeness of proofs and for the construction of consistent notions and definitions?"229 Thus the "logical process of building up the science of numbers" on the basis of the counting-practice does not depend on what the elements are, but on finding out the primitive mutually independent and consistent properties of the sequence $N$ and to "divest them from their specifically arithmetic character". This “divesting” is Plato's and Husserl's idealization; it is not a psychological process. One should quote also in its entirety $Z 73$, in order to make this clear:

"If in the consideration of a simple infinite system $N$ ordered by an Abbildung $\varphi$ we entirely neglect the special character of the elements, simply retaining their distinguishability and considering only the relationships in which they are placed to one another by the ordering Abbildung $\varphi$, then these elements are called natural numbers or ordinal numbers or simply numbers, and the base-element 1 is called the base-number of the number-sequence $N$. With reference to this freeing the elements from any other content (abstraction) we are justified in calling numbers a free creation of the human mind. The relations or laws which are derived entirely from the conditions $\alpha, \beta, \gamma, \delta$ in 71 and therefore are always the same in all ordered simple infinite systems, whatever names may happen to be given to the individual elements (compare 134), form the first object of the science of numbers or arithmetic".

${ }^{227}$ Tait 1993, 304. I have mentioned above, in footnote 191, McLarty's elaboration on this distinction between Plato's original theories and our modern use of 'Platonistic' and my discriminant use of 'realism' and 'Platonism'.

${ }^{228} Z$, Preface to the first edition (my italics). See also $S$ §1: "I regard the whole of arithmetic as a necessary, or at least natural, consequence of the simplest arithmetic act, that of counting, and counting itself as nothing else than the successive creation of the infinite series of positive integers in which each individual is defined by the one immediately preceding; the simplest act is passing from an already-formed individual to the consecutive one to be formed... Addition is the combination of any arbitrary repetition of the above-mentioned simplest act into a single act; from it in a similar way arises multiplication." (my italics).

${ }^{229}$ Letter to Keferstein, February 1890, 27, van Heijenoort 1967, 99-100 (Dedekind's italics). Also $Z 73$. 
In order to prevent a psychologistic misunderstanding, for example like that of Dummett, Tait presents Dedekind's abstraction as a typical logical abstractive procedure, contrasting 'logical' with the Aristotelean abstraction from empirical data to mathematical objects, and he sees Dedekind as a logicist rather than structuralist, arguing that what is essential is that propositions about the abstract objects translate into propositions about the things from which they are abstracted so that the truth of the former depends on the truth of the latter ${ }^{230}$. However what is at stake is really the abstract structure itself $f^{231}$, the total ordering imposed by an injective Abbildung $\varphi$ which makes a simple infinite System $S$ the chain of a distinguished singleton $\{\mathrm{e}\} \subset S$ (i.e. the least set containing $\{\mathrm{e}\}$ and closed under $\varphi$ ), rather than the abstract (i.e. logical in Frege's view) character of the natural numbers themselves. Dedekind's abstract numbers are uninterpreted elements, not logical objects. "The science of numbers" depends only on the theory of simple infinite sets, with axioms $\alpha, \beta, \gamma, \delta$, and not of the choice of any particular such System. Dedekind explains that this is why his ordinal numbers, "the abstract elements of the simple infinite System" are "something new, created by the mind". In a similar way he takes an irrational number to be something new, created and represented by, but not identical to the corresponding cut ${ }^{232}$. Frege cannot accept that one takes as primitive so unspecific properties of the numbers, because the statements of these properties do not have a determinate sense as long as we leave uninterpreted the shadowy elements; they are not complete sentences, hence they cannot express thoughts which may be judged once and for all true or false. In Frege's view, Dedekind's way to obtain generality is not logical, since logic is theory of truth (along with theory of inference).

5.2.3. Abbildung, One-to-one correspondence: Dedekind versus Frege

Digging for the foundations of arithmetic, both Dedekind and Frege come to recognize, but in very different ways, the essential role of one-to-one correspondence. The differences are those between a structural practice, which seeks no entity beyond the intrastructural relations, and the logicist view that regards identity of an object-name as that to be specified and replaces postulation of objects by explicit definition in terms of classes.

${ }^{230}$ Tait 1997. Parsons 1990 discusses Tait's view and offers a deep analysis of the notion of mathematical structure.

${ }^{231}$ I agree with Shapiro's opinion, according to which "The Dedekindian way is best conceived as addressing only [the structural aspect]", instead of giving at once by HP a sufficient axiom and a philosophical account (Shapiro 2005, 189).

${ }^{232}$ Letter to Weber, January 24, 1888, Dedekind 1930-32 III, 489-490. Compare Benacerraf 1965: no set-theoretic representation should be taken as defining the numbers. 
In $Z$, the primitive relation on Systems is inclusion, which is expressed in terms of an ähnliche Abbildung from a System $S$ into $S$. An Abbildung results from the "ability [Fähigkeit] of the mind to relate things to things, to let a thing correspond to a thing, or to represent [abbilden] a thing by a thing" ${ }^{233}$. Abbildung is representation or correspondence in general; it may be "ähnlich", that is one-one (injection), and more particularly, one-one from a System S onto its image (bijection). Is saying that Abbildung is a very general operation of the mind the same as saying that it is a purely logical notion? An affirmative answer ${ }^{234}$ would find partial justification in the expressions Dedekind uses in the first and the second preface of $Z$. But 'logic' is logic of the operative mind. Moreover, as a matter of fact, Dedekind introduces first, in the 1850s, the notions of System and Abbildung in his algebraic works and in his theory of algebraic numbers ${ }^{235}$, without speaking of logic. In addition to that, even in $Z$ the practical perspective is not really logical, since 'System' and 'Abbildung' are not defined or derived from logical concepts proper, such as Frege's 'concept' and 'relation'. Whereas Frege uses the one-to-one correspondence for defining equinumerosity by passing from arithmetical notions to purely logical ones, Dedekind uses the one-to-one correspondence for discriminating infinite systems from finite ones: a System $S$ is infinite if there is an ähnliche Abbildung (injection)

$$
f: S \mapsto T T \subset S \text { such as } f^{-1}(T)=S \text {, }
$$

that is $f$ is one-one from $S$ to $T, T \subset S$; $S$ is finite if it is not infinite. This definition is now classic - modulo a replacement of Dedekind's expressions by the current vocabulary of set theory. And $S$ is simply infinite (countable totally ordered set) if there is an ähnliche Abbildung $f: S \mapsto S$ such as $S$ is the $f$-chain of a singleton $\{\mathrm{e}\} \subset S$ and $\{\mathrm{e}\} \not \subset f(S)^{236} . S$ is a domain of uninterpreted (abstract) elements; for the natural numbers $N$ we specify the singleton $\{\mathrm{e}\}=\{1\}$. The structure of $N$ is that of any simply infinite System (any progression). Moreover, an ähnliche Abbildung $f$ defined on a domain $S$ into a domain $T$ is not identified with the set of the couples

$$
(x, f(x)), x \in S, f(x) \in T \text {. }
$$

${ }^{233} Z$, Preface to the first edition.
${ }^{234}$ E.g., Ferreirós $1999,229$.

${ }^{235}$ See, e.g., his papers on Groups from the years 1855-58, in Dedekind 1930-32 III, 439ff, where Emmy Nœther found the germ of his own "Homomorphiesatzes", and the famous "Xth Supplément" of the second edition of Dirichlet's lectures on the theory of numbers, 1871, where Dedekind defines the field structure and develops his general theory of ideals using settheoretical operations.

${ }^{236}$ The $f$-chain of a singleton $\{\mathrm{e}\}: f_{0}(\{\mathrm{e}\})$, is the intersection of all chains $K \subset S$ such that $\{\mathrm{e}\}$ $\subset K . K \subset S$ is a $f$-chain if $f(K) \subset K$. 
Then it may serve to connect not only different domains having the same structure, but also different structures which may be themselves satisfied by different domains. What matters is the one-to-one correspondence, not its domain and codomain. That will become very clear with Emmy Nœther's general homomorphism theorems (of groups, rings, modules, algebras), the roots of which their author found in Dedekind.

Frege considers one-one correspondence, let us say $\Phi$, not between numbers as finite multitudes (Hume) nor between sets, but between concepts, since he defines numbers as belonging to concepts; thus $\Phi$ is a binary relation-concept: we say " $a$ stands in the relation $\Phi$ to $b$ " and we write today $\Phi a b$. Like simple concepts dealing with an object $a$ in a judgement of the form " $a$ falls under the concept $F$ " $(F a)$, relation-concepts belong to pure logic $(G l$ $\S 70)$ : indeed, $\Phi$ is characterized independently of number, which is comparable to Dedekind's definition of simply infinite Systems independently of number. Then Frege defines equality between cardinal numbers in three steps.

1) Two concepts $F$ and $G$ are "equinumerous" $(F \approx G)$ if there is a $\Phi$ that correlates one-toone the objects falling under $F$ with the objects falling under $G$.

2) The cardinal number $n$ belonging to $F$ is the extension of the concept 'equinumerous with $F$, i.e. $\# F=$ the class of all concepts $G$ equinumerous with $F$ (explicit definition of the number $n$ ).

3) The cardinal number which belongs to the concept $F$ is equal to the cardinal number which belongs to the concept $G$, if the concept $F$ is equinumerous to the concept $G: \forall F \forall G$ (\#F= $\# G \leftrightarrow F \approx G$ ). Then, Frege passes on to the definition of individual numbers: 0 is the number of the concept 'not identical with itself', $n+1$ the number of the sequence of natural numbers ending with $n$.

Thus Frege uses concepts and relation-concepts (our - monadic, dyadic, triadic, etc. predicates) where Dedekind uses Systems (our sets). For Frege one-to-one relation is a binary relation (dyadic predicate), for Dedekind it is a special kind of Abbildung (an injection). From Frege's concepts and relations has been developed quantification theory; from Dedekind's Systems and Abbildung has been developed set theory and a "working structuralism"237. Now how does the latter stand against the former?

\subsection{Dedekind's chains and Frege's following in the f-sequence}

${ }^{237}$ McLarty 2008a, 360. 
In the Preface to the second edition of $Z$ (1893), Dedekind writes that he had not read $G l$ not until 1889, and in retrospect he recognizes "very close points of contact" between $Z$ and $G l$, especially between his concept of chain and Frege's following in a $f$-sequence, presented already in $B g$ and in $G l$ from $\S 79$ on. Speaking of "points of contact", as for two geometric curves, Dedekind points to two different paths. Dedekind adds that the "the definite expression the author [Frege] gives for the mode of inference from $n$ to $n+1$ clearly shows that here he stands on the same ground as me". On the same ground indeed ${ }^{238}$, but at diametrically opposite poles. For, from the outset, Frege's goal is to show that "even an inference like that from $n$ to $n+1$, which is apparently peculiar to mathematics, is based on general logical laws, and that there is no need of special laws for aggregative thought" ${ }^{\text {239; }}$ thus, if the goal is achieved, every arithmetical theorem "would be a logical law, [...], calculation would be inference", as written in $G l \S 87$, in accordance with the programme already stated in $B g$ : “... first to see how far one could get in arithmetic with inferences alone, supported only by the laws of thought that transcend all particulars. The course I took was first to seek to reduce the concept of ordering in a sequence to that of logical inference ${ }^{240}$, in order then to progress to the concept of number". Quite the reverse, Dedekind's achievement in $S$ shows that numerical total ordering < is, with the identity as well, the primitive relation, which permits the passing from rational numbers to real numbers without any notion of magnitude. In $Z$ the inference from $n$ to $n+1$ is reduced to an order-setting Abbildung ${ }^{241}$, injective but not surjective, defined on an infinite System whose elements are not necessarily numbers ${ }^{242}$. The performed order is inclusion $\subset$ of sets. For defining the general notion of a chain $(Z, 37)$ one need only a domain $S$ of undetermined elements and an Abbildung $\varphi$ with domain and codomain $S$; then, $K \subset S$ is a $\varphi$-chain of $S$ iff $\varphi(K) \subset K$. The intersection of all chains of $S$ containing $A, A \subset S$, i.e. the chain of $A,(Z, 44)$, permits to get the general theorem of complete induction (59), which, applied with $S=N$ and $\varphi$ injective, provides the arithmetical

${ }^{238}$ For the formal similarities between Dedekind's chains and Frege's following in a $f$ sequence see e.g. Demopoulos \& Clark 2005, 140-141.

${ }^{239} \mathrm{Gl}$, Introduction, $\S 45$, Beaney 1997, 86, 98, respectively: “The expressions 'multitude', 'set', 'plurality', due to their vagueness, are unsuitable for use in defining number" ('vagueness' obviously means multivocity).

240 Translating 'Folge' by 'consequence', in accordance with our current usage, would be misleading since Frege actually deals with inference.

${ }^{241}$ For the logical similarity with the ancestral relation, and for setting on a par Dedekind's introduction of the real numbers as corresponding uniquely to cuts and Frege's introduction of extensions as objects corresponding uniquely to concepts, see Boolos, 249-254.

242 Once again, Dedekind's generality through Abbildung differs from Frege's logical generality obtained by the ancestral relation. 
induction (80) and the theorem of definition by induction - finite recursion - (126). Dedekind's concept of chain is not reducible to a pure logical procedure, unless one counts sets and Abbildungen as being logical. This is certainly not Frege's interpretation. As to Dedekind himself, his conception of logic shows the role a certain idea of 'logic', understood as general arithmetic, played in the emergence of set theory and axiomatics, which is the opposite of a logicist reduction. Dedekind's immediate followers axiomatized set theory, interpreting Abbildung as mapping, while modern category-theorists rightly understand Abbildung as morphism, namely an arrow connecting structures. Despite his evocation of logic Dedekind's interpretation of Leibniz' “calculemus!" does not aim at constructing the calculus of reasoning, but at showing that reasoning, fundamentally, is arithmetic generalized to undetermined elements. What matters is the structural generalization, not the logical reduction, of arithmetic. The nuance is significant.

Actually, Dedekind ${ }^{243}$ and Frege agree to disagree not only on their interpretations of "the constitution/logic of the mind", but also on their conceptions of the nature of number. Frege writes: "Herr Dedekind, like myself, is of the opinion that the theory of numbers is a part of logic; but his work hardly contributes to its confirmation, because the expressions 'System' and 'a thing belongs to a thing', which he uses, are not usual in logic and cannot be reduced to acknowledged logical notions." Thus in Frege's opinion, set and membership are not of logical nature; Dedekind's reduction to sets is not a logical reduction. In other words, set theory is not logic. One cannot but admire Frege's perspicuous eye: indeed, in a language with the membership relation as a primitive term, such as first-order $Z F$, no mathematical relation is logical ${ }^{244}$. The question "What is logic?" might still be disputable, yet Frege's judgement confirms that Dedekind and Frege answer it differently ${ }^{245}$, and that lead to think that the demarcation between set theory and logic still is open to question.

\section{Conclusions}

${ }^{243} Z$, Preface to the second edition.

${ }^{244}$ Tarski shows that the answer to the question: "Is mathematics reducible to logic?" depends on the choice of the language. On the assumption of Tarski's criterion of logicality, which is set-theoretically defined through invariance under permutations of the domain of individuals, the answer is affirmative in Russell's simple type theory, negative in Zermelo's first-order system. Tarski 1986 prompted a rich discussion on the very nature of logic which is still open: Tarski's criterion is accepted as a necessary but not sufficient condition for defining logicality in semantic terms (McGee), and it is criticized for reducing logic to set-theory (Feferman).

${ }^{245}$ Gödel stands on the side of Frege: he distinguishes between 'set' or 'class' on the one hand, and 'concept' on the other hand, and he aims too at establishing a "theory of concepts", Gödel 1947, 1964. See Wang 1987, 1996. 
1. My first point is that a bias is introduced by isolating Dedekind's two essays on numbers, or even $Z$ alone, the one of the very rare pieces ${ }^{246}$ where the author regards arithmetic as a part of logic. Dedekind's work concerns a wide range of mathematical topics comprising geometry, infinitesimal analysis, arithmetic, algebra, topology, and in every domain he inaugurated a structural way to do mathematics, without necessarily making a link with logical concerns. For instance, it appears from his theory of ideals that isolating the "inner properties" of the concept to be defined (created), i.e. spelling the NSC that must be satisfied and that hold for a definition of the concept of 'ideal' and from which one can derive new theorems, can be achieved in close connection with the substantive mathematical results at hand (Gauß and Kummer on number theory) and without calling for logic. ${ }^{247}$ Moreover, his work contains neither a specifically logical development nor a body of articulated philosophical views. Nevertheless his scattered remarks about the nature of number or the essence of continuity form a coherent picture, which pertains to knowledge and epistemology rather than to being and ontology. ${ }^{248}$ Dedekind endorses the Kantian split between epistemology and ontology, whereas Frege renews the Ancient connection between the two.

2. Dedekind writes that Frege stands on the same ground as himself. Logic is the common ground. But one naturally cannot give to 'logic' and 'logical' under Dedekind's pen the same meaning as that we learnt from Frege. In particular "Dedekind's logic" has nothing to do with an analysis of language, nor with a theory of inference, nor with a theory of mathematical truth. Now, if one persists in taking à la lettre the affirmation that arithmetic is a part of logic, one should make precise that the building tools, viz. System and Abbildung, are not logical in Frege's sense of the word. For there is no room in Frege's logical realm for the aggregative thought nor for the kind of generality promoted by Dedekind's Abbildung: the operative mind representing a thing by a thing allows substituting the second for the first, not because the two are identical, but just because they play the same role in determined conditions. Dedekind's Abbildung conflicts straight out with Frege's concern for strict identity. As Dedekind's work shows everywhere, identity is much less fruitful than analogy (representation in Dedekind's

\footnotetext{
${ }^{246}$ As noted by Ferreirós, in two other pieces Dedekind presents his systems as logic: in a sketch of $Z$ (Ferreirós 1999, 225) and in "Systemlehre der Logik" (Dedekind 1930-32 II, 113). ${ }^{247}$ Dugac 1976, Edwards 1983, and Avigad 2006. Dedekind highlights the inner link between his concept of cut and his concept of ideal, e.g. in the Introduction of his paper "Sur la théorie de nombres entiers algébriques", Dedekind 2008, 235-251.

248 Stein $(1988,247)$ rightly points out that Dedekind's work is "quite free of the preoccupations with 'ontology' that so dominated Frege, and had so fascinated later philosophers".
} 
wording), which affords not a substantial but a functional identity. The undetermination of the elements is, from a mathematical point of view, not a flaw vis-à-vis the question of truth, but the condition for bringing to the light structures, which may apply to domains of different elements and, thus, facilitate substantial interactions and substantial development of mathematical stuff.

3. For Dedekind, what matters are not the numbers themselves but their structure. Arithmetic is fundamental not only because numbers are applied everywhere, but because we can, following the arithmetical laws, calculate with things which are not numbers. What matters is not what can be said of numbers in themselves, but as satisfying the four conditions brought to the light $(Z, 71,73)$. And this is why we can say that arithmetic is a formal structure of our experience. ${ }^{249}$ The "logic of the mind" is arithmetic taken generally. As Dedekind writes, "every thinking man, even if he is not clearly aware of that, is an arithmetic-man, an arithmetician" ${ }^{250}$, for thinking is representing a thing by a thing, relating a thing with a thing. I understand the famous phrase "arithmetic is a part of logic" as meaning that arithmetic affords also a rational (logical) norm of thinking.

4. Dedekind's construction in $Z$ shows, in fact, that Dedekind assimilates logic to set theory rather than the reverse -, what Frege refused for good reasons ${ }^{251}$. However, the demarcation between logic and set theory stressed by Frege is still in debate. In a semantic approach, which is based on set theory, different invariance criteria across structures are proposed for capturing logical notions (by Tarski, Sher, McGee, Van Benthem, Feferman, and Denis Bonnay among others). In a syntactic proof-theoretic approach, logicality is defined in terms of some set of basic inference patterns (Gentzen, Prawitz, Martin-Löf, Feferman, and others). Worth mentioning are also the game-theoretic approach and the computational approach among others. Logicality may also be understood in a "holistic" way, concerning a whole language. Different stances are taken as to the status of the second-order and higher-order quantification. Logicians vindicate the autonomy and priority of logic over set theory, but they diverge on what is logic. Parsons and Feferman defend Quine's view according to which second-order and higher-order quantification is nothing else but "set theory in sheep's clothing" on the ground that the meaning of such quantifiers depends on what sets exist ${ }^{252}$.

\footnotetext{
${ }^{249}$ Kitcher 1986, 328.

${ }^{250}$ Dugac 1976, 315 (my italics).

${ }^{251}$ Parsons 1965, §§VI, VII.

${ }^{252}$ Feferman 1999, 22.
} 
According to Parsons "the justification for not assimilating high-order logic to set theory would have to be an ontological theory like Frege's theory of concepts as fundamentally different from objects, because "unsaturated"", and even in that case "high-order logic is more comparable to set-theory than to first-order logic" $" 253$. Feferman argues that operations of first-order logic with equality have the same meaning independently of the domain of individuals over which they are applied. By contrast, Boolos, Resnik, Shapiro, and others refuse to regard the line between first- and second-order logic as the line between logic and mathematics and they take second-order and higher-order quantification to be genuine logic. Boolos' following judgement is noteworthy: “Of special interest in Dedekind's work... is the use of what Quine would regard as set-theory and what I... would call logic" ${ }^{254}$. Actually, as van Benthem pinpoints, there are many intuitive aspects of logicality, and no one of the various formal characterizations exhausts the notion ${ }^{255}$. Yet such a liberalism does not kill the search after criteria for logical notions as universal notions independent from what there is, and, in particular, criteria not definable in set-theoretic terms ${ }^{256}$. I will recall here the structural analogy between proofs and programmes expressed by the Curry-Howard isomorphism, which states a structural correspondence between formulas and types such that logic and arithmetic appear to be two faces of the same process.

5. A last remark: it is risky to cut a piece of work from its practical and historical context. I would strongly speak in favour of what is now named the "practical turn" in philosophy of science and also in favour of "the historical turn" in analytic philosophy. I think we gain a more accurate view on mathematical or logical concepts and methods when we start with mathematical or logical practices and build philosophical reflections from the practical ground. I think also we gain a better philosophical analysis and appraisal of a piece of work when we do not ignore its historical entrenchment.

\section{Bibliography}

\section{Avigad Jeremy}

2006 Methodology and metaphysics in the development of Dedekind's theory of ideals, in The architecture of modern mathematics, Ferreirós J. \& Gray J. (eds.), Oxford University Press, 159-186.

Beaney Michael

\footnotetext{
${ }^{253}$ Parsons 1965, 166.

${ }^{254}$ Boolos 1998, 254.

${ }^{255}$ Van Benthem 2002.

${ }^{256}$ Feferman 2010.
} 
1997 The Frege reader, Oxford, Blackwell Publishing Ltd.

Belna Jean-Pierre

1996 La notion de nombre chez Dedekind, Cantor, Frege, Paris, Vrin, Mathesis.

Benacerraf Paul

1965 What numbers could not be, Philosophical Review 74, $\mathrm{n}^{\circ}$ 1, 47-73. Reprint in

Benacerraf P. \& Putnam H., 1983, 272-294.

Benacerraf Paul \& Putnam Hilary (eds.)

1964 Philosophy of mathematics, Selected Readings, Prentice Hall, New Jersey.

Second ed. 1983, Cambridge University Press.

Boolos George

1995 Frege's theorem and the Peano's axioms, The Bulletin of Symbolic Logic 1,

Number 3, 317-326, in Boolos 1998, 291-300.

1998 Logic, Logic, and Logic. Cambridge, Harvard University Press.

Burgess John

1984 Review of Crispin Wright's Frege's conception of numbers as objects,

Philosophical Review 93, 638-640.

Bynum Terrell Ward

1976 The evolution of Frege's logicism, in Schirn 1976, 279-286.

Cantor Georg

1899 Letter to Hilbert November 15, 1899, Georg Cantor Briefe, in Meschkowski H. and Nilson W., Springer-Verlag, 1991, p. 414 L.

1932 Abhandlungen mathematischen und philosophischen Inhalts, Zermelo E. (ed.);

Carnap Rudolf reprint Olms, 1966.

1930 Die alte und die neue Logik, Erkenntnis 1, 12-26.

1931 Die logizistische Grundlegung der Mathematik, Erkenntnis 2, 91-123. English

transl. in Benacerraf P. \& Putnam H. 1983, 41-51.

Dedekind Richard

1872 Stetigkeit und irrationale Zahlen, Braunschweig, Friedrich Vieweg und Sohn; reprint in Dedekind 1930-32, III, 315-334.

1888 Was sind un was sollen die Zahlen? Braunschweig, Friedrich Vieweg und

Sohn ; reprint in Dedekind 1930-32, III, 335-391.

1930-32 Gesammelte mathematische Werke I, II, III, Nœther E., Fricke R., Ore Ö. eds., Braunschweig, Vieweg.

1937 Briefwechsel Cantor-Dedekind, Cavaillès J. \& Nœther E. eds., Paris, Hermann. French translation in Cavaillès, Philosophie mathématique, 1962, Paris, Hermann.

2007 Essays on the theory of numbers, English transl. W.W. Beman, The Open Court Publishing Company, 1901; http://www.gutenberg.org/ebooks/21016 (is missing the Preface to the third edition, published in 1911).

2008 La création des nombres, French transl. of $S, Z$ and pieces relative to both writings, with Introductory Notes and footnotes by Benis Sinaceur H., Paris, Vrin.

Demopoulos William

1995 Frege's Philosophy of Mathematics, Cambridge, Harvard University Press.

1998 The philosophical basis of our knowledge of number, Noûs 32, $\mathrm{n}^{\circ}$ 4, 481-503.

2000 On the origin and status of our conception of number, Notre Dame Journal of

Formal Logic 41, n 3, 210-226.

Demopoulos William and Clark Peter

2005, The logicism of Frege, Dedekind and Russell, in Shapiro (ed.) 2005, chap. 5, 129-165.

Detlefsen Michael 
2010 Intuition, rigor, scope and the motives for Dedekind's logicism, communicated by the author.

Dugac Pierre

1976 Richard Dedekind et les fondements des mathématiques, Paris, Vrin.

Dummett Michael

1991 Frege and other philosophers, Oxford, Clarendon Press.

Edwards Harold

1983 Dedekind's invention of ideals, Bulletin of the London Mathematical Society 15, 8-17.

Feferman Solomon

1999 Logic, Logics, and Logicism, Notre Dame Journal of Formal Logic 40(1), 3154.

2010 Set theoretical invariance criteria for logicality, Notre Dame Journal of Formal Logic 51(1), 3-20.

Ferreirós José

1993 On the relations between Georg Cantor and Richard Dedekind, Historia mathematica 20, 343-363.

1999 Labyrinth of thought. A history of set theory and its role in modern mathematics, Birkhäuser. Second ed. with added postscript, 2007.

Frege Gottlob

1879 Begriffsschrift. Eine der arithmetischen nachgebildete Formelsprache des reinen

Denkens. Halle, L. Nebert; available at http://gallica.bnf.fr. English transl. in van

Heijenoort 1967, 1-82.

1884 Die Grundlagen der Arithmetik. Eine logisch-mathematische Untersuchung über den Begriff der Zahl. Breslau, Koebner. Original text and English transl by J.L. Austin, Oxford, Basil Blackwell, second revised ed. 1953. Partial transl. in Beaney 1997. 1893-1903 Grundgesetze der Arithmetik, begriffsschriftlich abgeleitet. 2 Bde. Jena, Pohle; reprint Olms, 1966; available at http://gdz.sub.uni-goettingen.de. Partial English transl. by M. Furth, Berkeley-Los Angeles-London, University of California Press, 1964.

1902 Letter to Russell, in van Heijenoort 1967, 126-128.

1967 Kleine Schriften, Angelelli ed., Hildesheim, Olms.

Gödel Kurt

1979 Posthumous writings, Hermes H. \& alii eds, Oxford, Blackwell.

1944 Russell's mathematical logic, in Collected Works II, Feferman S. \& alii (ed.),

New York-Oxford, Oxford University Press, 102-141.

1964 What is Cantor's continuum problem?, in Collected Works II, 254-270.

Gabriel Gottfried \& Kienzler Wolfgang (eds.)

1997: Frege in Jena: Beiträge zur Spurensicherung, Würzburg, Königshausen \& Neumann.

Hale Bob \& Wright Crispin

2005, Logicism in the twenty-first century, in Shapiro (ed.) 2005 chap. 6, 166-202.

Heck Jr Richard G.

1993 The development of arithmetic in Frege's Grundgesetze der Arithmetic, The

Journal of Symbolic Logic 58, 2, 579-600; reprint in Demopoulos 1995.

2000 Cardinality, counting, and equinumerosity, Notre Dame Journal of Formal Logic

41, $\mathrm{n}^{\circ} 3,187-209$.

Hellman Geoffrey

2005 Structuralism, in Shapiro 2005, 536-562.

Hilbert David 
1899 Die Grundlagen der Geometrie, Leipzig, Teubner; 10th ed., Stuttgart, Teubner, 1968.

1905 Über die Grundlagen der Logik und der Arithmetik, Verhandlungen des dritten internationalen Mathematiker-Kongresses (Heidelberg, 1904), Leipzig,

Teubner. English transl. in van Heijenoort 1967, 129-138.

Hodes Harold T.

1984 Logicism and the ontological commitments of arithmetic, The Journal of

Philosophy 81, n 3, 123-149.

Kitcher Philip

1986 Frege, Dedekind, and the philosophy of mathematics, in Frege synthetized, Haaparanta L. \& Hintikka J. (eds.), , Springer, 299-343.

Kitcher Philip \& Aspray William (eds.)

1988 History and philosophy of modern mathematics, Minneapolos, Minnesota University Press.

Landau Edmund

1917 Richard Dedekind, Nachrichten der Königliche Gesellschaft der Wissenschaften zu Göttingen, Geschäftliche Mitteilungen, 50-70.

Lipschitz Rudolf

1877 Lehrbuch der Analysis, Erster Band: Grundlagen der Analysis, Bonn, Von Max Cohen \& Sohn.

McCarty David Charles

1995 The mysteries of Richard Dedekind, in From Dedekind to Gödel, Hintikka J. ed., Dordrecht-Boston-London, Kluwer Academic Publishers, 53-96.

McLarty Colin

1993 Numbers can be just what they have to, Noûs 27, n 4, 487-498.

2005 'Mathematical Platonism' versus gathering the dead: what Socrates teaches Glaucon, Philosophia Mathematica (III) 13, 115-134.

2008a What structuralism achieves, in The philosophy of mathematical practice, Mancosu P. (ed.), Oxford University Press, 354-369.

2008b There is no ontology here, in Mancosu P. (ed.), 370406.

Parsons Charles

1965 Frege's theory of number, reprint in Mathematics in philosophy, Cornell University Press, Ithaca, 1983, second ed. 2005, 150-175.

1976 Some remarks on Frege's conception of extension, in Shirn 1976, 265-278.

1977 What is the iterative concept of set?, reprint in Benacerraf-Putnam 1983, 503529.

1990 The structuralist view of mathematical objects, Synthese 84, 303-346.

Putnam Hilary

1967a The thesis that mathematics is logic, in Mathematics, matter, and method: philosophical Papers I, Cambridge University Press, 1975, 12-42.

1967b Mathematics without foundations, in Mathematics, matter, and method: philosophical Papers I, Cambridge University Press, 43-59, first published in The

Rayo Augustín Journal of Philosophy 64, $\mathrm{n}^{\circ} 1$ (January 1967), 5-22.

2005 Logicism reconsidered, in Shapiro (ed.) 2005, chap. 7, 203-235.

Reck Erich H.

2003 Dedekind's structuralism: an interpretation and partial defense, Synthese 137, 369-419.

2008 Dedekind's contributions to the foundations of mathematics, Stanford Encyclopedia of philosophy. 
Resnick Michael

1981 Mathematics as a science of patterns: Ontology and reference, Noûs 15, 529-550.

Russell Bertrand

1903 The principles of mathematics, London, George Allen\& Unwin Ltd.

1919 Introduction to mathematical philosophy, London: Allen \& Unwin.

Schlimm Dirk

2000 Richard Dedekind: Axiomatic Foundations of Mathematics. M.A. Thesis,

Carnegie Mellon University, Pittsburgh.

Schirn Matthias

1976 Studien zu Frege I. Logic und Philosophy der Mathematik, Schirn M. (Hrsg.)

Frommann-Holzboog, Stuttgart-Bad Cannstatt.

Shapiro Stewart

2000 Frege mets Dedekind : a neologicist treatment of real analysis, Notre Dame

Journal of Formal Logic 41, ${ }^{\circ}$ 4, 335-364.

2005 Oxford handbook of philosophy of mathematics and logic, (ed.), Oxford: Oxford University Press.

Sieg Wilfried \& Schlimm Dirk

2005 Dedekind's analysis of number: systems and axioms, Synthese 147, 121-170.

Stein Howard

1988 Logos, logic, and logistiké: some philosophical remarks on nineteenth-Century transformation of mathematics, in Kitcher Ph. \& Aspray W. (eds.) 1988, 238-259.

Tait W. W.

1986a Truth and proof: The Platonism of mathematics, Synthese 69, 341-370.

1986b Critical notice: Charles Parsons' Mathematics in philosophy, Philosophy of science 53, 588-607.

1993 Review essay: some recent essays in the history of the philosophy of

mathematics: a critical review, Synthese 96, 293-331.

1997 Frege versus Cantor and Dedekind: on the concept of number, in Early analytic philosophy, Tait W. W. (ed.), Chicago, Open Court, 213-248.

Tarski Alfred

1986 What are logical notions, posthumous paper edited by Corcoran J., History and Philosophy of Logic 7, 143-154.

Van Heijenoort Jean

1967 From Frege to Gödel : a source book in mathematical logic, 1879-1931,

Cambridge, Mass., Harvard University Press.

Van Benthem John

1989 Logical constants across varying types, Notre Dame Journal of Formal Logic 30

(1), 315-342.

2002 Invariance and Definability: two faces of logical constants, in W. Sieg, R.

Sommer and C. Talcott, eds., Reflections on the Foundations of Mathematics. Essays

Wang Hao in Honor of Sol Feferman. ASL Lecture Notes in Logic 15, 426-446.

1987 Reflections on Kurt Gödel, A Bredford book, Cambridge (Mass.)-London, The MIT Press,.

Wright Crispin

1983 Frege's conception of numbers as objects, Aberdeen University Press.

2000 Neo-Fregean foundations for real analysis: some reflections on Frege's

constraint, Notre Dame Journal of Formal Logic 41, n 4, 317-334.

Zermelo Ernst 
1908a Neuer Beweis für die Möglichkeit einer Wohlordnung, Mathematische Annalen 65, 107-128.

1908b Untersuchungen über die Grundlagen der Mengenlehre I, Mathematische Annalen 65, 261-281; English transl. in van Heijenoort 1967, 199-215.

1909 Sur les ensembles finis et le principe de l'induction complète, Acta mathematica 32, 185-193.

$\exists X \varphi(X) \rightarrow \varphi(\{x: \psi(x)\}$ 
